\title{
A Study of Challenges in Designing and Construction of Skyscrapers
}

\author{
Ar. V. Vijayasree \\ Professor \\ School of Environment Architecture and Design \\ SRM Institute of Science and Technology, \\ Ramapuram campus \\ Chennai, India
}

\begin{abstract}
Skyscrappers have been around for a long time and have always been dominant landmarks in many cities, visible from far and wide.Tall Buildings are perhaps the most keenly debated building typology currently in existence. Opinion on their contribution to the urban agenda is usually divided; strongly for, or strongly against.It is important to bring in design considerations of their appropriateness to a setting, and how they could be inspired by, and relate to, that setting. The role of architecture is to satisfy the physical, social and aesthetic needs of the society where architects play a crucial role in effecting change in responsible for the social and environmental imports of their professional activitie.
\end{abstract}

Keywords—Skyscrappers,landmarks, architecture,Tall Buildings

\section{INTRODUCTION}

Skyscraper, is a very tall, multistoried building. The name first came into use during the 1880s, shortly after the first skyscrapers were built, in the United States. The development of skyscrapers came as a result of the coincidence of several technological and social developments. The term skyscraper originally applied to buildings of 10 to 20 stories, but by the late 20th century the term was used to describe high-rise buildings of unusual height, generally greater than 40 or 50 storiesThe increase in urban commerce in the United States in the second half of the 19th century augmented the need for city business space, and the installation of the first safe passenger elevator (in the Haughwout Department Store, New York City) in 1857 made practical the erection of buildings more than four or five stories tall. Although the earliest skyscrapers rested on extremely thick masonry walls at the ground level, architects soon turned to the use of a castiron and wrought-iron framework to support the weight of the upper floors, allowing for more floor space on the lower stories. James Bogardus built the Cast Iron Building (1848, New York City) with a rigid frame of iron providing the main support for upper-floor and roof loads.It was, however, the refinement of the Bessemer process, first used in the United States in the 1860s, that allowed for the major advance in skyscraper construction. As steel is stronger and lighter in weight than iron, the use of a steel frame made possible the construction of truly tall buildings. William Le Baron Jenney's 10-storyHome Insurance Company Building (188485 ) in Chicago was the first to use steel-girder construction

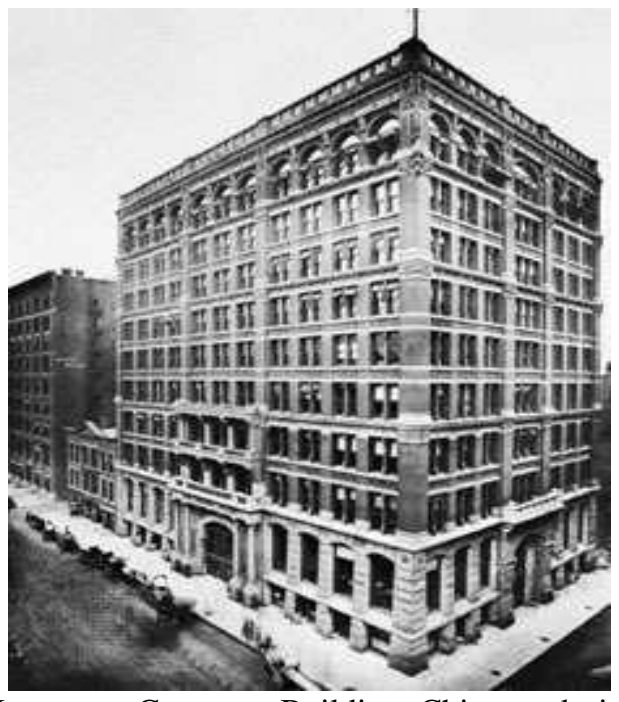

Home Insurance Company Building, Chicago, designed by

William Le Baron Jenney, 1884-85 (demolished 1931)

Jenney's skyscrapers also first employed the curtain wall, an outer covering of masonry or other material that bears only its own weight and is affixed to and supported by the steel skeleton. Structurally, skyscrapers consist of a substructure of piers beneath the ground, a superstructure of columns and girdersabove the ground, and a curtain wall hung on the girders.

As the population density of urban areas has increased, so has the need for buildings that rise rather than spread. The skyscraper, which was originally a form of commercial architecture, has increasingly been used for residential purposes as well.

The design and decoration of skyscrapers have passed through several stages. Jenney and his protégé Louis Sullivan styled their buildings to accentuate verticality, with delineated columns rising from base to cornice. There was, however, some retention of, and regression to, earlier styles as well.

As part of the Neoclassical revival, for instance, skyscrapers such as those designed by the firm of McKim, Mead, and White were modeled after Classical Greek columns. The Metropolitan Life Insurance Building in New York City (1909) was modeled by Napoleon Le Brun after the Campanile of St. Mark's in Venice, and the Woolworth 
Building (1913), by Cass Gilbert, is a prime example of neoGothic decoration.

Even the Art Deco carvings on such towers as the Chrysler Building (1930)and the Empire State Building (1931) which were then considered as modern as the new technology, are now viewed as more related to the old ornate decorations than to truly modern lines.

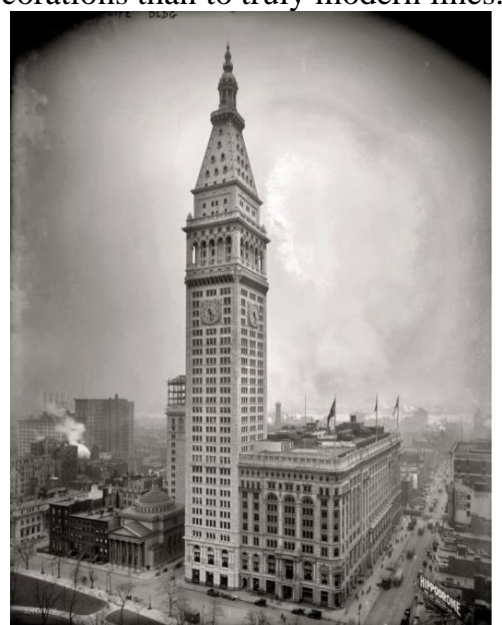

The Metropolitan Life Insurance Building in New York City (1909)

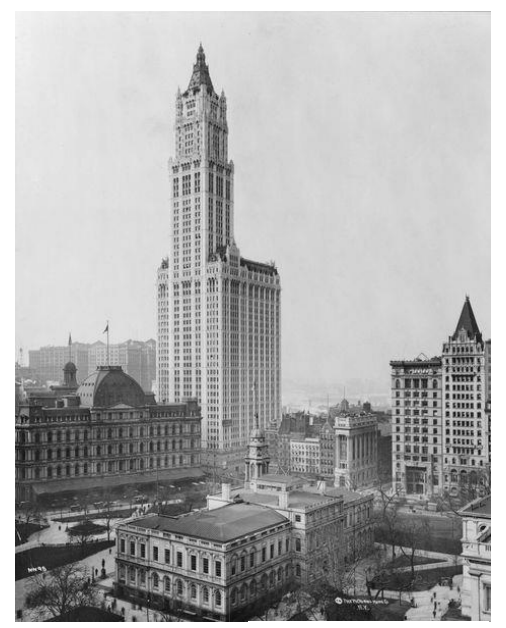

Woolworth Building, in New york (1913)

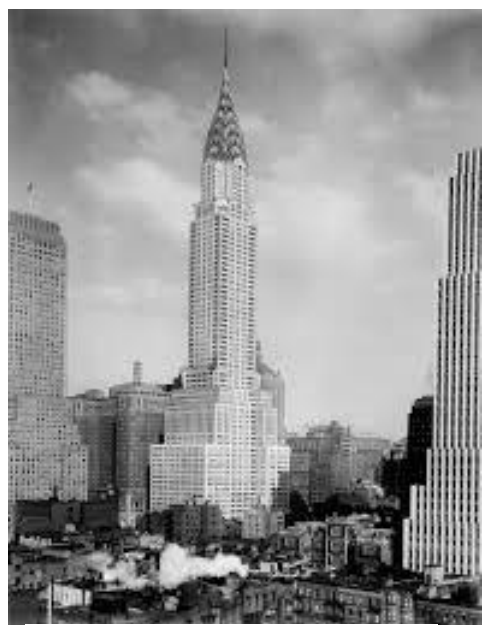

Chrysler Building, New york (1930)

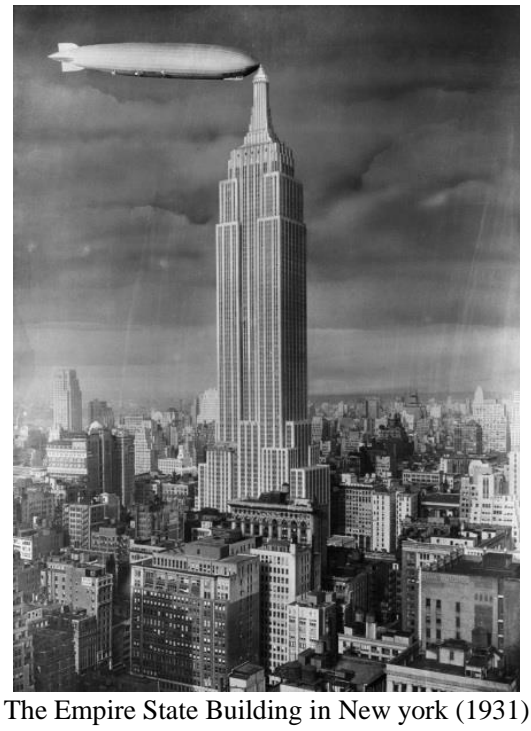

Good structural design is important in most building designs, but particularly for skyscrapers since even a small chance of catastrophic failure is unacceptable given the high prices of construction. This presents a paradox to civil engineers: the only way to assure a lack of failure is to test for all modes of failure, in both the laboratory and the real world. But the only way to know of all modes of failure is to learn from previous failures.

Thus, no engineer can be absolutely sure that a given structure will resist all loadings that could cause failure, but can only have large enough margins of safety such that a failure is acceptably unlikely. When buildings do fail, engineers question whether the failure was due to some lack of foresight or due to some unknowable factor.

In this era of world the skyscrapers are considered as the landmarks and getting developed throughout the world below is few comparison between the new skyscrapers in the height with different usage of it

I. First Skyscrapper in the World:

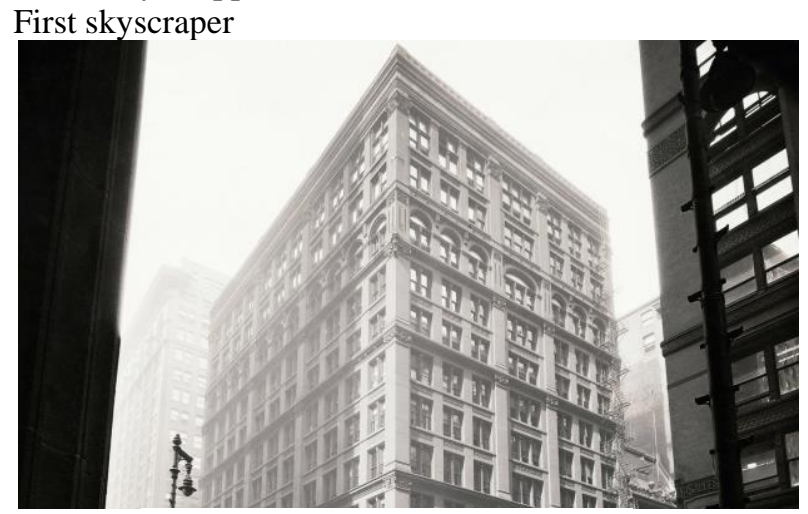

Home Insurance Building, Chicago

Home Insurance Building, which rose to its impressive height of10 storeys (and, after an 1890 addition, 12) by means of metal, rather than just masonry.Legend has it that Jenney, an engineer by training and an École Centrale Paris classmate of Gustave Eiffel (designer of the eponymous tower), first 
suspected that an iron skeleton could hold up a building when he saw his wife place a heavy book atop a small birdcage, which easily supported its weight.

This opened a new chapter in the history of towers, helped by the Great Chicago Fire (in which more than three square miles of the mostly wooden central city burned to the ground in 1871), and by Chicago's surging 1880s economy.For obvious reasons, when the New York Home Insurance Company wanted a new Chicago headquarters in the city's cleared-out downtown, they wanted it fireproofed - but they also wanted it tall, accommodating "a maximum number of small offices above the bank floor". Jenney's metal-framed design won their open contest, not only thanks to the relative fire-resistance of its materials, but to the additional protection offered by its outer iron columns, covered in stone.

Unlike its predecessors - the generations of large buildings supported by nothing but their own masonry walls - the Home Insurance Building wouldn't have to get thicker, darker, stuffier and heavier to get taller. It weighed only a third as much in iron and steel as it would have in stone.

Not everybody immediately accepted the soundness of Jenney's design. "Where is there such a building?" the committee asked when presented with the plan. "Your building at Chicago will be the first," Jenney replied.

After construction got underway, the Home Insurance Company and the City of Chicago temporarily halted the project in order to investigate further whether the building could really stand up on its own. Soon after, Jenney got the idea to $s \quad$ witch from an iron frame to an exotic new material, steel, using a supply offered to him by the CarnegiePhipps Steel Company of Pittsburgh. This aroused yet more skepticism. A 1962 Life magazine retrospective on the origins of skyscraper recalls how "an aroused critic terrified his fellows at a protest meeting by impersonating the writhings of a steel beam exposed to a sudden change of temperature".But in the event, not only did the Home Insurance Building stand up, it came to stand for an entire architectural movement, loosely termed the Chicago School, which gave built form to the proud, square-shouldered, technologically forward American ambition that drove the country forward in the late 19 th and early 20th century.

cleared-out downtown, they wanted it fireproofed - but they also wanted it tall, accommodating "a maximum number of small offices above the bank floor". Jenney's metal-framed design won their open contest, not only thanks to the relative fire-resist ance of its materials, but to the additional protection offered by its outer iron columns, covered in stone.

Unlike its predecessors - the generations of large buildings supported by nothing but their own masonry walls - the Home Insurance Building wouldn't have to get thicker, darker, stuffier and heavier to get taller. It weighed only a third as much in iron and steel as it would have in stone.

Not everybody immediately accepted the soundness of Jenney's design. "Where is there such a building?" the committee asked when presented with the plan. "Your building at Chicago will be the first," Jenney replied.
After construction got underway, the Home Insurance Company and the City of Chicago temporarily halted the project in order to investigate further whether the building could really stand up on its own. Soon after, Jenney got the idea to switch from an iron frame to an exotic new material, steel, using a supply offered to him by the Carnegie-Phipps Steel Company of Pittsburgh. This aroused yet more skepticism. A 1962 Life magazine retrospective on the origins of skyscraper recalls how "an aroused critic terrified his fellows at a protest meeting by impersonating the writhings of a steel beam exposed to a sudden change of temperature".But in the event, not only did the Home Insurance Building stand up, it came to stand for an entire architectural movement, loosely termed the Chicago School, which gave built form to the proud, square-shouldered, technologically forward American ambition that drove the country forward in the late 19th and early 20th century.

Though aesthetically unified only by what some historians term the "commercial style", the architects of the Chicago School shared an interest in creating innovative tall buildings, an effort supported not just by steel but by the electricity needed to keep the lights on and the elevators running. The group included architects Dankmar Adler and Louis Sullivan, whose firm would give Frank Lloyd Wright his start, and Daniel Burnham, who in 1902 would design New York City's still-standing and still-striking early skyscraper, the Flatiron Building.

By developing and refining the concept of the skyscraper, the Chicago School's influence not only changed the way we built cities in the 20th century, ushering in previously unthinkable densities, but remains visible in the newest additions to major skylines today. Jenney's design gave Chicago's modestly sized central business district - now known as the Loop - a way to expand upward, rather than outward. It was a concept whose limits New York, and later other world capitals, would keep pushing over the following century.

The 1940s saw the emergence of a "second Chicago School", which took the pioneering work in new directions - upward, for the most part. This movement gained momentum during German modernist Ludwig Mies van der Rohe's time at Chicago's Illinois Institute of Technology, innovating with 3D "tube" structures, just as the first Chicago school innovated with steel beams. Bangladeshi engineer Fazlur Khan made the boldest initial steps with tube structures, using them to design the city's John Hancock and Sears (now Willis) Tower.

These tube structures have continued to make possible the kind of skyscrapers that set world records and shape their cities' identities - buildings like New York's World Trade Center, Kuala Lumpur's Petronas Towers and even Jeddah's Kingdom Tower, which upon completion will, at 167 storeys, be the world's tallest building. Even though the skyscraper itself counts as a quintessentially American invention, the most daring examples now appear mainly outside the US.

Jenney believed in designing buildings for the long term, so future generations could "read the feelings and aspirations of those who erected them". Alas, his masterpiece fell to the wrecking ball in 1931 to make way for another skyscraper, the Field Building (now the LaSalle Bank Building). But its 
legacy lives on in every major city, places we simply cannot imagine without the far taller, sleeker skyscrapers built over the past 130 years, each and every one of which owes something to the Home Insurance Building.

\subsection{Demand of highrise buildings}

A High-rise building is essentially a building with a small footprint, small roof area, and very tall facades. And what differentiates it from the conventional low rise and medium rise buildings is that it needs special engineering systems due to its height (Scott, 1998)...Later, a better definition was coined: "A high-rise is any structure where the height can have a significant impact on evacuation."

As the inevitable result of growing population and intensifying urbanization, high-rise residential towers have become more prevalent in many cities, replacing vast areas of vernacular houses. During the building of these towers, the housing process has been radically, thinking about the long history of human dwelling. Today, the building of large numbers of dwellings in high-rise residential towers is controlled by a few parties (architects and developers), which is a dramatic change from tradition.

Essentially, the early High-rise building was an economic phenomenon in which business was the engine that drove innovation. Design was tied to the business equation, and style was secondary to the primary factors of investment and use. The priorities of the men who put these buildings were economy, efficiency, size and speed (Huxtable, A. and Ada, L.., 1992).

The reasons for adopting high-rise buildings could be solutions for density problems and lack of available land for development, sometimes tall buildings more about power, prestige status, where they play an important role in meeting occupier demand for large prestigious headquarters, and aesthetics than efficient development.

A historic race to the sky and the marking of a city resulting in a battle between tradition and modernity affects the form of the city, as well as the culture and political landscape (Sorkin, M.,2001).The high-rise buildings have now replaced grand mosque minarets as one of the typical phenomenon of high-intensity development.

A new era is dawning for High-Rise Buildings, the destruction of the World Trade Centre's 110-story twin towers on Sept.11, 2001, sent a chilling message to the world. Since that time, a battle has been ranging in engineering code making, fire protection and political circles over whether tall buildings are safe, and the role of public officials in the process, moving towards an increasingly significant technical sophistication.

\subsection{Needs of high rise buildings}

Tall buildings are built out of necessity as one of a wide range of tools to achieve high density development. They provide the opportunity to control urban sprawl with their relatively small foot print. Identifying what unique characteristics a tall building brings could be represented in the need for a particular built form- the concentration of activity-the proximity to important facilities for large numbers of people which is more than "image" and being a more sustainable form of development .Some appear to be opposed to tall buildings wherever they are located or whatever they look like. The positive and negative influences through development by high-rise towers and tall building could be evaluated within certain factors including (Social Environmental -Economics-Emotional-Safety (FireEarthquakes).

Tall buildings have been blamed for crime, mental breakdowns, the generation of urban pathologies-they deform the quality, the function, by overloading the infrastructure and the public realm of the streets that contain them .Criticizing the building of High-rise building as being about power prestige than efficient development, some critics say super-tall buildings are too hard and expensive to build. Addressing the kind of risks that a tall structure is likely to encounter in its, life time, risks of safety problems are usually associated with unknown disasters like for example blocking fire escape (NFPA, 2006).

High-rise buildings bring impacts at strategic and local levels. The huge people load of a high building, particularly at peak times, may overload the cities infrastructure-its public transport, roads and utilities. The size of a building has important direct influences on our emotional

response. More and more planners are being asked to consider streetscape in addressing a community's quality of life; streetscapes play a central role in place making and providing spaces for social interaction. Understanding their proper design and the impact of that design is essential in planning healthy and vibrant communities. (Bekkering, H., et al, 1997).

Shadow restrictions are designed to limit the height of buildings so as to ensure sufficient sunlight in the city. Buildings that reach new heights pose numerous engineering and technological problems relating to such issues as building a sufficiently strong foundation, ventilation, heating, cooling, lighting, transportation (elevators, stairs, parking), communication, electrical power, plumbing, wind resistance, structural integrity, fire protection and building security(Glaeser, L. and Jesse, S. 2001). There also is a host of public issues connected with the increases in employment density brought about by tall structures, such as transportation congestion and environmental concerns (Sukkoo, K. 2002).

There is rising concern for the safety from fires, and in order to develop appropriate plans for combating high-rise incidents, there needs to be an understanding of the whole process .Basic concept behind fire safety measures: The standards relating to fire safety in buildings broadly consist of two major parts, namely, those relating to fire protection and those relating to fire evacuation. England has such a requirement supported by a British Standard (BS 5588 Part 5) requiring fire-fighter lifts in buildings exceeding $18 \mathrm{~m}(60 \mathrm{ft})$ in height. Fire-fighter lifts are also provided in the Petronas Towers, one of the world's tallest buildings in Kuala Lumpur, Malaysia. Fire fighter lifts, required in tall buildings, are being discussed to improve both the safety and efficiency of fire fighting operations.

\subsection{Urban context}

The urban fabric of a city is a reflection of the events that took place, growth, transition and change, where buildings conveys 
messages about the way in which they were put together in the architectural sense. A key design policy consideration is that development should respond appropriately to its context, but that context should be defined to include the visual, social, functional and environmental dimensions. Architecture is concerned with culture, society and economics as well as the surrounding environment. The interaction of all these aspects is vital in defining the characteristics of a place. The built environment of a city is thus a product of its socio cultural and political context, which in turn impacts both architecture and planning disciplines. Tall buildings can be equally appropriate grouped in clusters or located alone. The suitability of a particular site for a tall building development will, however, depend on site specific circumstances and the proposal in question.

The approach to the design of tall buildings has changed rapidly; nowadays the building design has become an integral part of a complex process. In many American and Canadian cities, almost arctic conditions have been created by thoughtless placement and detailing of tall buildings. In Sun, Wind and Comfort, Peter Bosselmann, apart from pointing to the undesirable shadow effect, gives examples of climate deterioration due to wind around free-standing high-rise buildings, among them the channel effect, the corner effect and the gap effect. William $\mathrm{H}$.Whyte, writing about conditions in New York, points to the consequences by mentioning that "It is now well established that very tall freestanding towers can generate tremendous drafts down their sides.

Problems were results of the dark caverns by shadows of tall buildings: depressed workers due to lack of sun, an increase in, winter diseases "congestion" in the streets, and the possibility of fires. Tall buildings always cast shadows, and change the patterns of air movements around them, affecting their cleansing qualities.

Many major cities, requires every proposal for a new Highrise building to include a "Sunlight Access and Shadow Impact Study". The study guidelines state that new buildings should not cast significant shadows on public parks, plazas, waterways, beaches or playgrounds. Each building is evaluated on its shape, height and orientation, focusing on environmental factors, by creating better relationships and harmony between buildings and their urban and environmental contexts.

Despite differences in definitions, perspectives and priorities, sustainability remains a critical challenge, sustainability and the aim that development should constitute an environmental benefit, is a new objective, concerning drawing "design" into issues of landscape quality, ecological, soundness, environmental capacity, pollution control and public transport viability (Punter, J. and Carmona, M. 1997).Sustainability is about improving the quality of human life while living within the supporting eco- systems. Sustainable design, dealing with efficient use of energy, while utilizing the latest smart construction techniques, is now an essential ingredient of any development. Construction as a whole uses more of the world's energy and material resources than any other activity, from the perspective of environmental sustainability, the discussion of indoor environment quality must be among the most important topics to be addressed. John gummer, environmentalist and former British Secretary of state for the Environment emphasized that "buildings of low quality cannot provide the ingredients of sustainability". In addition to technology other mechanisms need to be found to use energy efficiently (Ellis, C.1998).

Ecological sustainability could be classified into three basic sets of strategies. The first strategy is one we call design for efficient operations costs. That means efficient energy, materials, efficiency by design configuration by passive means with low environmental impact. Second level is design for efficient fire costs. That means the energy equipment and assembly that gives you efficient first costs with low environmental

impact. And eventually if we have sufficient data to do this, we should design for efficient end cost and end use.

If you are working in different climatic zones, then you have the hot seasons and the cold seasons to deal with, and you have the two mid- seasons. So you have to design the enclosure, the skin as a responsive environmental filter for energy efficiency.

\subsection{Advantages and disadvantage of skyscrapers Advantages:}

One of the advantages of having many scrapers in your city is all of the different views that it gives you. These views could be so stunning to that it leads to a tourist attractive, which could intern bring in money for the business or the city that it is in.

Another on of the major advantages that is very obvious is space. These skyscrapers have so much space inside of the building that it could fit more than one company in it. By having more than one company in the building it helps not take up as much space in the city.

Another advantage of the skyscrapers is the symbolism. The symbolism of the tower could be something like a tragedy happened in that spot and they are making its spot and naming the building after it. This could be a major advantage for the city cause it could be a major attraction to the city which intern would bring in more money to the city.

They become cost effective when they provide high value floorspace in congested affluent population choke points.

There is no one to disturb and people can relax with the peace of mind watching the skylince of the city and get beautiful panaromic view

\section{Disadvantages:}

One of the major concerns of the skyscraper is the safety of the building. These huge structures are way more possible to be hurt by some natural disaster because of how big they are. The bigger the building means that they have to a greater foundation so if there is a natural disaster and there is any problem with the foundation there could be a major problem. One other cost that is a huge problem for building skyscrapers is the cost of the buildings. These building are so massive that they cost so much that people often think that they are not worth the money.

A disadvantage has been the high environmental cost of their construction and lift / elevator power consumption. That disadvantage might be reduced by new technologies 
Very highbuildings people wont have contact with the roads and the ground this will make them disconnect from the nature and surroundings

\section{CHAPTER 3: SKYSCRAPERS FAILING IN HISTORY}

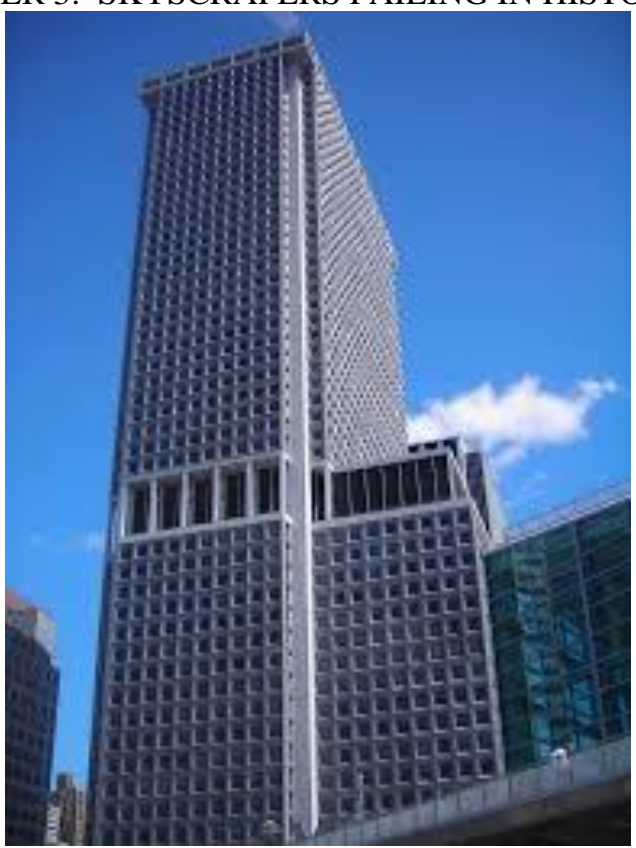

One New York Plaza was a 50 storey office building. A fire occurred on the $33^{\text {rd }}$ floor on the August 15,1970. Workers from the $32^{\text {nd }}$ floor discovered the fire two gaurds and a telephone company emloyee took an elevator to the $39^{\text {th }}$ floor with the intention of notifiying the occupents on the fire because the elevator was called to the fire floor by the fire, the elevator stopped on the $33^{\text {rd }}$ floor. The two gaurds died but the telephone company employee survived.The supply of the air fans had been shut down early in the fire but the return fans continued to run.

\subsection{MGM Grand Hotel}

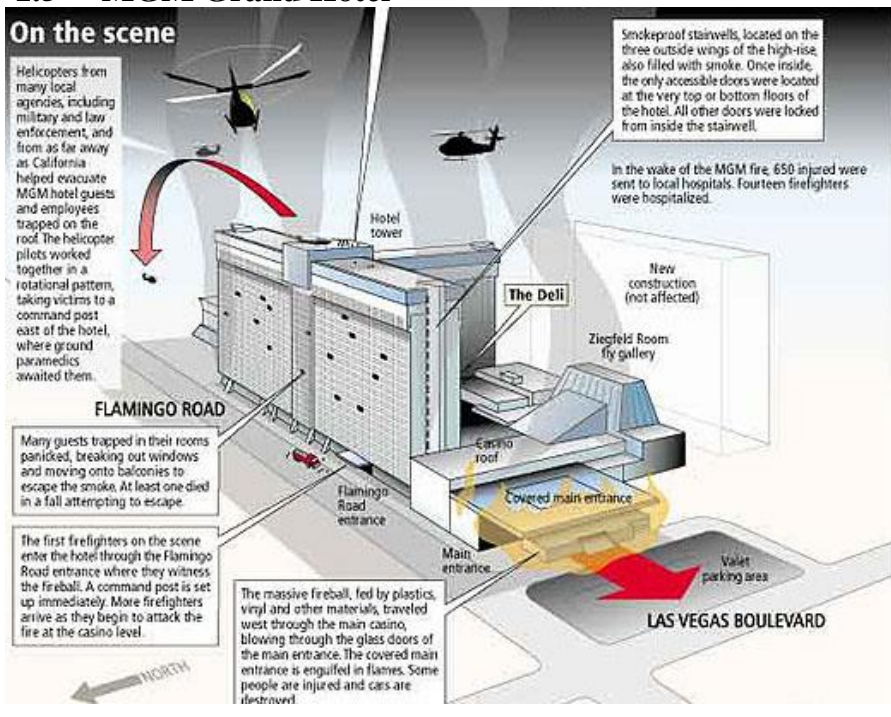

A fire at the MGM Grand Hotel on the november 21,1980 resulted in the deaths of 85 guests and the hotel employees.About 600 others were injured and approximately 35 fire fighters sought medical attention during and after the fire. The high rise building constructed in the early 1970s. Consisted of the 21 stories of guest rooms situated above a large, ground level complex comprised of a casino,showrroms,convention facilities, jai lai fronton , and mercantile complex. The hotel was partially sprinked, but major areas including the Main casino and the Deli ,the area of the fire originwere not sprinkeled about 3400 registred guestes were in the hotel at the fire time. Most probable cause of the fire was heat produced by an electrical ground fault within a combustible concealed space in the waltresses serivng station of the deli

\subsection{EMPIRE STATE BUILDING}

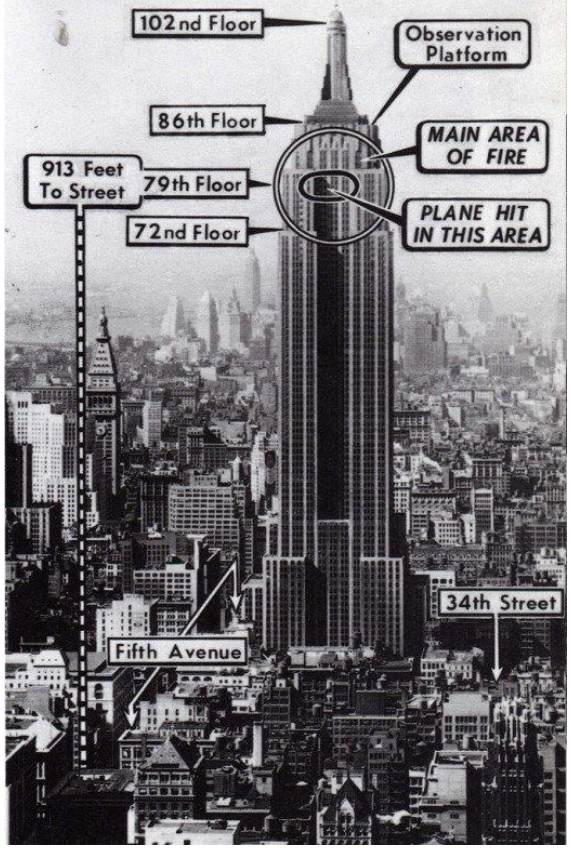

At 9:40 am on Saturday, July 28, 1945, a B-25 Mitchell bomber, piloted in thick fog by Lieutenant Colonel William Franklin Smith, Jr., crashed into the north side of the Empire State Building, between the 79th and 80th floors, where the offices of the National Catholic Welfare Council were located. One engine shot through the side opposite the impact and flew as far as the next block, where it landed on the roof of a nearby building, starting a fire that destroyed a penthouse. The other engine and part of the landing gear plummeted down an elevator shaft. The resulting fire was extinguished in $\mathbf{4 0}$ minutes. Fourteen people were killed in the accident. Elevator operator Betty Lou Oliver survived a plunge of 75 stories inside an elevator, which still stands as the Guinness World Record for the longest survived elevator fall recorded. Despite the damage and loss of life, the building was open for business on many floors on the following Monday. The crash helped spur the passage of the long-pending Federal Tort Claims Act of 1946 as well as the insertion of retroactive provisions into the law, allowing people to sue the government for the accident. A year later, another aircraft narrowly missed striking the building. 


\section{CHAPTER 2: DESIGNING IN SKYCRAPERS}

\subsection{Energy conservation method}

High rise apartment buildings have unique challenges and needs when it comes to energy. Keep reading to explore how high-rise apartment building owners can make their property as efficient as possible and ultimately more comfortable and affordable for residents.

residential and commercial buildings are responsible for $40 \%$ of the total energy consumption each year. The main factors in residential energy consumption relate to heating and cooling of the space.

\section{- Windows Materials and Frames}

Windows are a defining feature of high rise buildings. While single family homes have windows in most rooms, they are much more prevalent in many high rises, sometimes stretching from floor to ceiling. Windows help to reduce lighting needs, but they can also allow heat to enter or escape the apartments.

\section{- Low-Emissivity Film}

Also known as Low-E film, the product can be applied to windows to block $97 \%$ of UV rays and keep heat out during summer. In the winter months, the film actually helps to retain heat in homes.

\section{- Window \& Framing Materials}

The materials used for the framing and windows themselves will impact the efficiency of your high rise. Look for windows that have low-e or double glazing and insulated frames that are made of vinyl, wood or fiberglass.

\section{- Tight Construction}

The construction of a building is just as important as the systems installed in it. Air leaks can add up to $30 \%$ to the heating and cooling costs of apartments and a substantial amount of wasted energy. Tight construction is focused on eliminating leaks, gaps and holes that are found throughout a building. It begins with the framing of a building and continues all the way through to the finishes.

The fewer holes, seams and joints a structure has the tighter the construction will naturally be. The use of sheet materials helps to minimize these occurrences. Proper sealing is also a key component of tight construction. But this expands beyond sealing around windows and doors. During construction, many holes are created by electricians, plumbers, builders, etc. Some are easily accessible while others are hidden within walls. It is virtually impossible to seal every hole, but making a conscious effort to reduce large gaps (known as effective leakage area) throughout the building will have the biggest return in improved energy efficiency.

\section{FEW POINTS TO BE CONSIDERED}

The tops and bottoms of the building

Elevators

Vestibules

Rooftop access points

Stairwells
High rise buildings that use tight construction techniques have far superior insulation, which dramatically increases energy efficiency. Another benefit of tight construction in a high rise is the noise reduction, which tenants will appreciate.

\section{Tight construction techniques :}

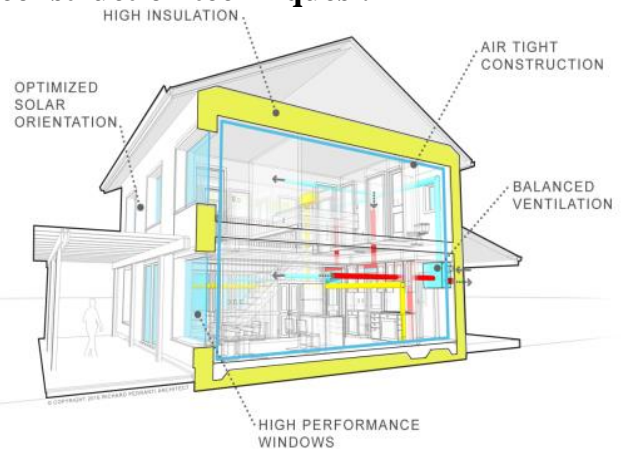

The more effective the building envelope--the walls, roof, windows and foundation of the house--the more energy efficient and comfortable the house will be. Tight construction and high performance windows reduce heat loss during the winter months, block heat gain in summer, and result in significant energy savings.

Other benefits include improved indoor air quality (by keeping out pests, dust, radon and outdoor air pollutants), reduction of outside noise, and fewer condensation problems, which can lead to mold and mildew. Careful attention to the building envelope during construction will also help eliminate the need for difficult and costly improvements in the future and can increase the resale value of the home.

\section{Ventilation Systems}

Tight construction needs to be paired with adequate mechanical ventilation systems to ensure good air quality. This alone makes investments in ventilation worthwhile, but from an energy efficiency standpoint, it is just as important. Ventilation systems are able to draw air out of apartments. Using vents when cooking or showering in the summer can help keep living spaces cooler.

\section{Tight Ductwork}

Leaks within the ductwork cause a $20 \%$ air loss on average. Instead of cool and hot air moving into the living spaces it is lost in the cavities of the building. A thorough inspection of the duct system will undercover the poor connections, holes, blockages, duct tape failures, insulation loss and kinks that negatively impact airflow and efficiency. Special attention should be given to:

All duct connections

Returns

Refrigerant lines

Air filter slots

\subsection{Building Automation :}

Building automation means comprehensive solutions and services for controlling the heating, ventilation, air conditioning, lighting, shutters and sun shields as well as the integration of electric power distribution -ranging across individual rooms, entire floors and complete buildings and also managing distributed property areas. 
Buildings are responsible for about $40 \%$ of the total energy consumption within the European Union (EU). With Directive 2010/31/EU, the Energy Performance of Buildings Directive (EPBD), the European Union pursues the goal to improve the energy efficiency of properties by $20 \%$ until 2020, compared to the reference year 1990. Amongst the most important measures specified are the creation of an energy certificate for buildings (or energy 'passport') and the determination of minimum requirements for buildings.

In the European standard EN 15232, "Energy Performance of Buildings - Effects of the Building Automation and the Building Management", the components of building automation systems are evaluated with regard to their effect on the energy consumption of buildings.

In accordance with the new standard, building automation systems (BAS) are divided into four different performance classes (Fig. 1/1): not energy-

efficient; buildings with such systems have to be modernized, new buildings may not be equipped with these systems.

\section{3 water supply}

Since water doesn't flow uphill, high rise buildings depend on pumps to "lift" the water to the upper floors. A typical municipal water system doesn't have enough "head" (the pressure that pushes water up) to do the job by itself.

Large buildings with internal wet pipe or dry pipe fire suppression systems have two different water systems. Buildings with chilled water and hot water air conditioning systems plus fire sprinklers have three systems. This means there are separate pumps for each system, usually located in mechanical rooms or sprinkler rooms. These pumps may be operated in circuits where additional pumps are required at higher floors, to maintain pressure on each system without overloading the primary pumps.

Depending on the design of the building, there may be mechanical or plumbing rooms on different levels with pressure tanks in each to regulate the water supply pressure to each system, decreasing overpressure when pumps are running, and to maintain pressure when the pumps cycle off.

Water is a heavy liquid, so the pumping system simply has to be capable of making heavy lifts to get the water to the top floor of a high rise building under enough pressure for the plumbing, fire sprinkler, and air conditioning systems to work properly. When you consider that pushing the water up one foot requires 0.43 pounds of pressure, $(1 \mathrm{~m}=\sim 1 \mathrm{kPa})$ a $500 \mathrm{ft}$ $(150 \mathrm{~m})$ tall building would require 215 pounds $(\sim 150 \mathrm{kPa})$ of pressure, which is higher than the rated strength of most pipes. This is why pumps must be installed at intervals to lift the water, or high pressure pipe systems and a high pressure pump must be used with pressure reducing valves located at the supply to each floor.

Another issue is the waste water drainage system. Water falling $500 \mathrm{ft}(150 \mathrm{~m})$ creates a lot of force, so drain lines have to have special vents to relieve pressure created when the waste water flows through the pipes.

\section{TYPES:}

\section{1.single booster system}

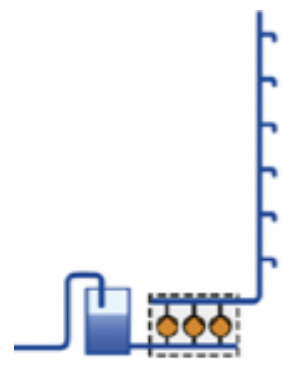

A water tank is placed in front of the pump system and filled with water from the mains. This allows the capacity of the mains to be lower than the building's peak demand, ensuring constant pressure even in peak flow situations. The break tank is filled with water during low consumption periods and ensures a uniform water supply to the booster pumps at all times.

\section{Zone-divided system}

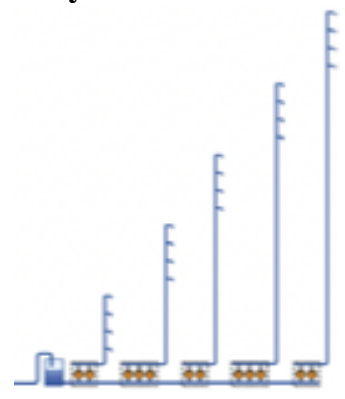

The supply system is split into several zones supplying a maximum of 12 floors each. This ensures adequate water pressure on all floors without using pressure relief valves. The minimum pressure on the upper floor in each zone is kept at 1.5 - 2 bar. The maximum pressure on the lowest floor in each zone does not exceed $4-4.5$ bar.

\section{Roof tanks}

ensure both water pressure and water supply in case of power failure. This solution requires pressure reduction valves on each floor in order to avoid undesired high static pressures at the tap, which creates unacceptable noise while tapping.

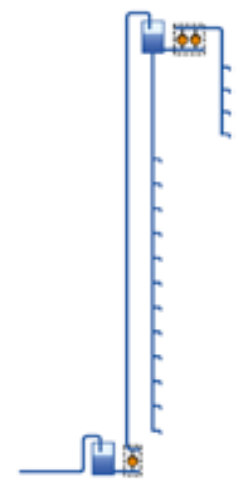

In this model the upper six floors require a separate booster system in order to create sufficient pressure. The static pressure there is too low due to the insufficient geometric height to the roof tank. 
4. Series-connected systems with intermediate break tanks

draw on several other systems, utilizing centrally-placed break tanks to supply both the taps in its own boosting zone and all the zones above it. With this system, a building is divided into smaller and more manageable pressure zones of 12 floors each. Every zone is then served by its own booster set.

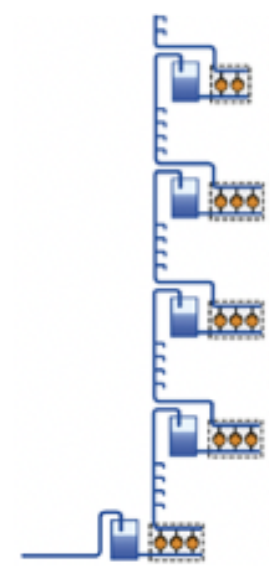

No pressure reduction valves are required and in case of electrical breakdown the tanks will be able to supply pressure and water for up to 12 hours. However, the tanks take up valuable space within the building, reducing the room available for revenue generation.

\section{A series-connected system}

\section{觜}

operates on the same principles as the previous system, but without the intermediate break tanks. STEPThis enables an effective usage of power because the water is only pumped to the zone where it is used and not past it.

However, complete control is very important. When a consumer draws water on the upper floors, the booster systems must deliver the water from the bottom of the building.

\section{CHAPTER 3 :CONSTRUCTION TECHNIQUE}

\subsection{Slip frorm construction}

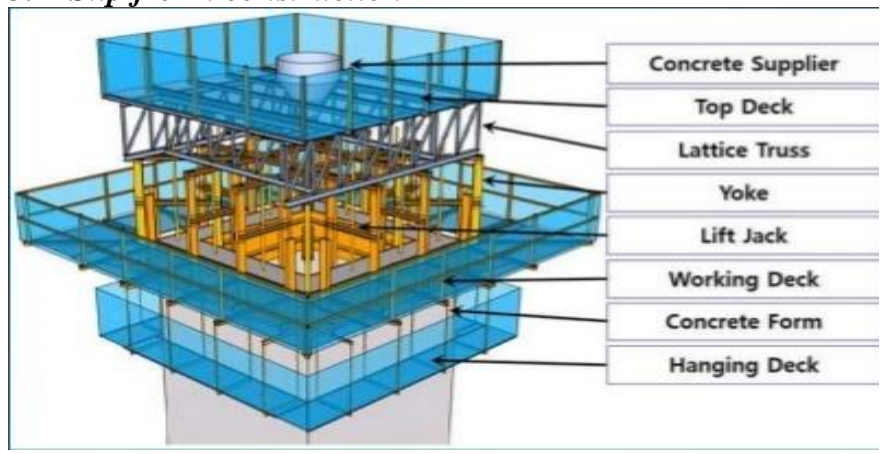

Slip forming, continuous poured, continuously formed, or slipform construction is a construction method in which concrete is poured into a continuously moving form.Slip forming is used for tall structures (such as bridges, towers, buildings, and dams), as well as horizontal structures, such as roadways. Slipforming enables continuous, noninterrupted, cast-in-place "flawless" (i.e. no joints) concrete structures which have superior performance characteristics to piecewise construction using discrete form elements. Slip forming relies on the quick-setting properties of concrete, and requires a balance between quick-setting capacity and workability. Concrete needs to be workable enough to be placed into the form and consolidated (via vibration), yet quick-setting enough to emerge from the form with strength. This strength is needed because the freshly set concrete must not only permit the form to "slip" by the concrete without disturbing it, but also support the pressure of the new concrete as well as resist collapse caused by the vibration of the compaction machinery

\section{2 climb from construction}

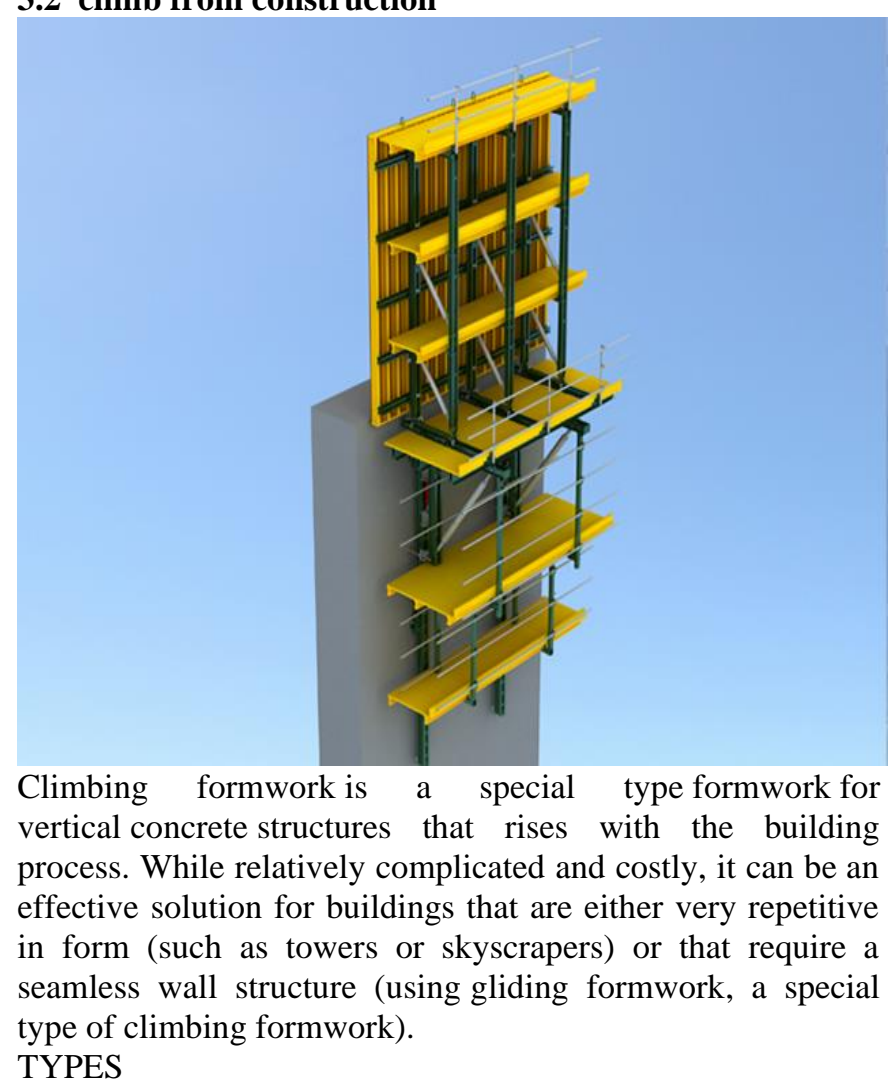

Climbing formwork (crane-climbing): in this type of climbing formwork, the formwork around the structure is displaced upwards with the help of one or more cranesonce the hardening of the concrete has proceeded far enough. This may entail lifting the whole section, or be achieved segmentally.

Climbing formwork (self-climbing): In this type of formwork, the structure elevates itself with the help of mechanic leverage equipment (usually hydraulic). To do this, it is usually fixed to sacrificial cones or rails emplaced in the previously cast concrete. 
Gliding formwork: This type of formwork is similar to the self-climbing type above. However, the climbing process is continuous instead of intermittent, and is usually only interrupted for a very short time (for example to fix the mounting mechanisms to new anchoring points). The advantage is that it will produce seamless structures, but it requires a continuous, uninterrupted process throughout, with serious potential quality and stability problems if the pour has to be stopped

\section{3 system column form work}

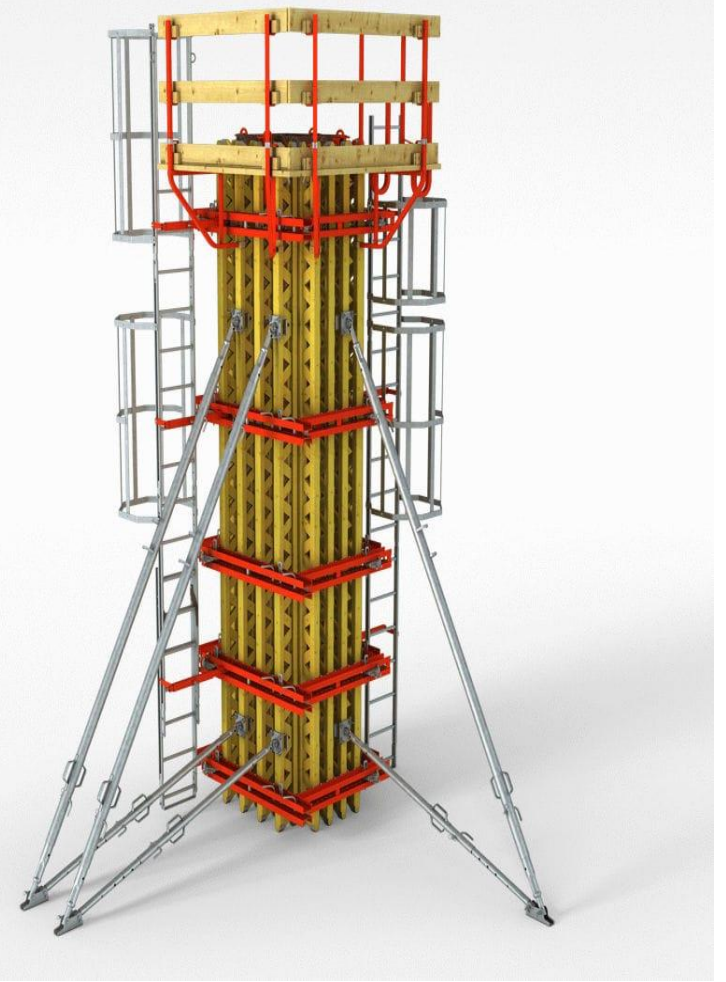

The column formwork systems now available are normally modular in nature and allow quick assembly and erection on site while minimisinglabour and crane time. They are available in steel, aluminium and even cardboard (not reusable but recycled) and have a variety of internal face surfaces depending on the concrete finish required. Innovations have led to adjustable, reusable column forms which can be clamped on-site to give different column sizes

\section{4 vertical pannel system}

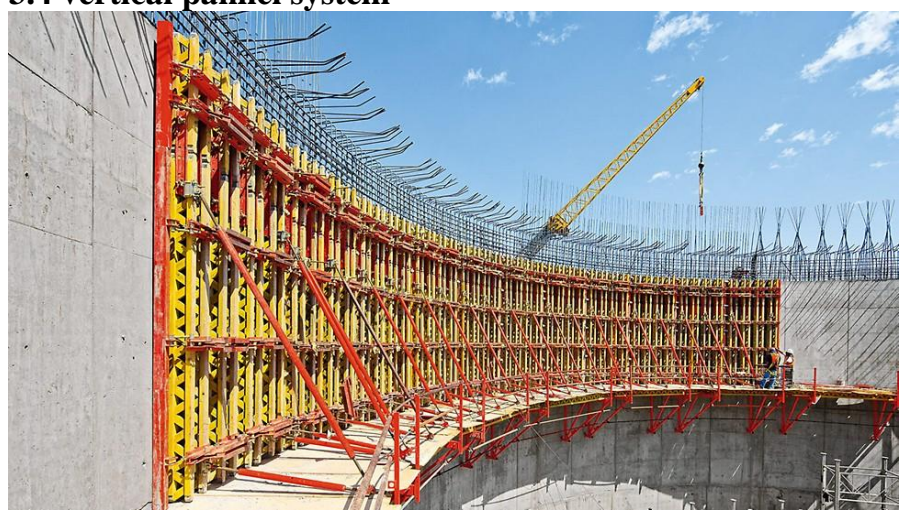

Crane-lifted panel systems are commonly used on building sites to form vertical elements and usually consist of a steel frame with plywood, steel, plastic or composite facing material.

The systems are normally modular in nature, assembly times and labour costs are considerably lower than traditional formwork methods with far fewer components required. They offer greater opportunities for reuse for different applications on

site.

Panel systems are extremely versatile and the larger cranelifted versions can be used for constructing standard concrete walls, perimeter basement walls, columns and in conjunction with jumpform climbing systems.

\section{5 jump from}

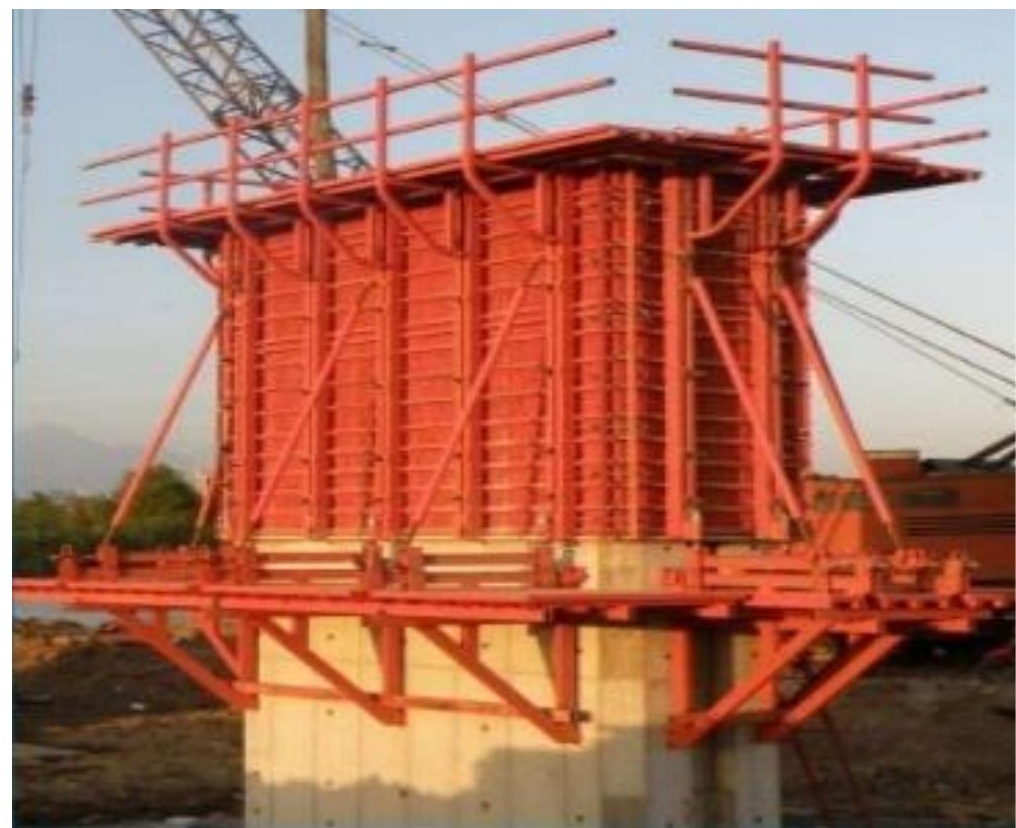

Generally, jumpform systems comprise the formwork and working platforms for cleaning/fixing of the formwork, steel fixing and concreting. The formwork supports itself on the concrete cast earlier so does not rely on support or access from other parts of the building or permanent works. Jumpform, here taken to include systems often described as climbing form, is suitable for construction of multistory vertical concrete elements in high-rise structures

1.Normal jump/climbing form: units are individually lifted off the structure and relocated at the next construction level using a crane. Crane availability is crucial.

2.Guided-climbing jumpform: also uses a crane but offers greater safety and control during lifting as units remain anchored/guided by the structure.

3.Self-climbing jumpform: does not require a crane as it climbs on rails up the building by means of hydraulic jacks. 


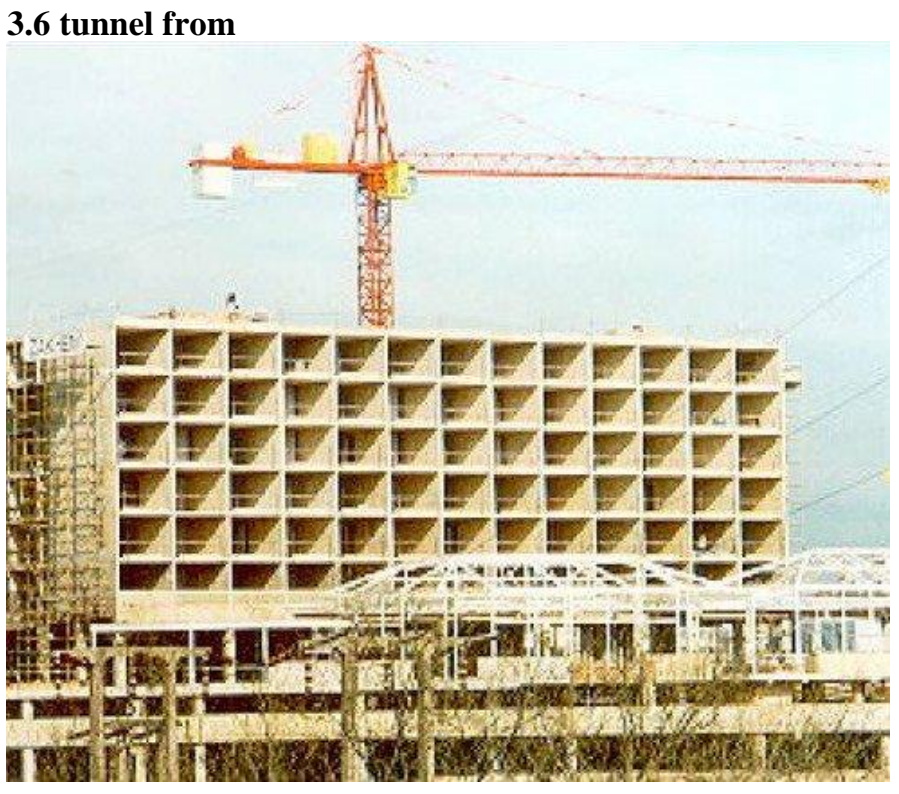

Tunnel form is a formwork system that allows the contractor to cast walls and slabs in one operation in a daily cycle. It combines the speed, quality and accuracy of factory/off-site production with the flexibility and economy of in-situ construction and is recognized as a modern method of construction (MMC).

The result is a cellular reinforced structure, the surfaces of which are sufficiently high quality to require only minimal finishing for direct decoration, while the end walls and facades are easily completed with thermally insulated units that can be clad as required.

The system creates an efficient load-bearing structure for use in a wide variety of applications. It is particularly effective in projects suited to repetitive cellular construction such as residential blocks, hotels, student accommodation, barracks and prisons.

\section{CHAPTER 4: STRUCTURAL SYSTEM}

A building needs to be stabilised for horizontal load and to achieve this, several different structural systems can be chosen. All of the different systems have evolved from the traditional rigidly jointed structural frame.

The fundamental design for all these structural systems have been to placed as much of the load-carrying material as possible around the buildings external fringe to maximise its flexural rigidity.

For all structural systems, advantage can be taken by locating the main vertical members and, with the compressive stresses from self- weight, suppress the lateral load tensile stresses.

This to avoid net tension in the vertical members and uplift in the foundations. For some structural systems it is necessary to have self-weight at the outer vertical members in order to achieve this.

\subsection{Types of structural systems}
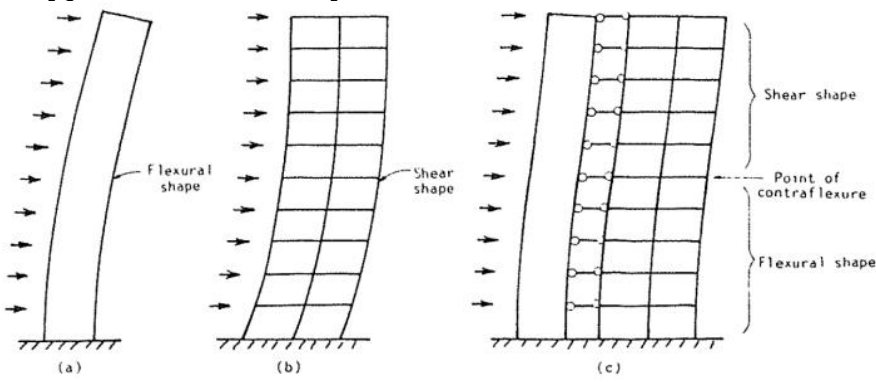

a)bending deflection

b)Shear deflection

c)Total
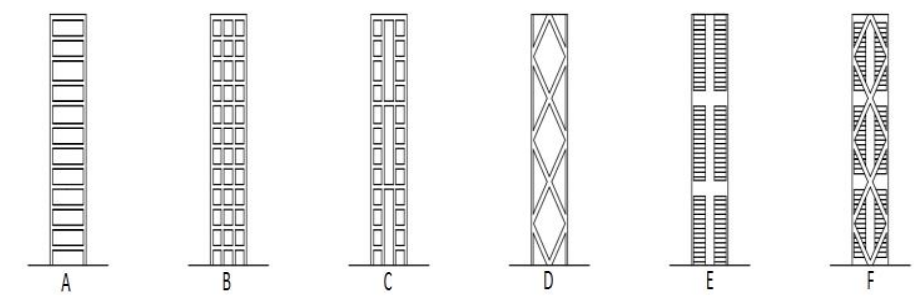

A) represents a framed tube system, B) a bundled tube system, C) a tube in tube system, D) a diagonalised system, E) a core and outrigger system and F) a hybrid system

\subsection{Framed tube systems}

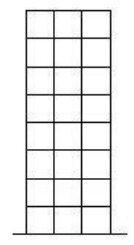

Frame
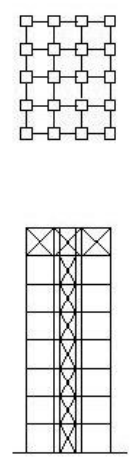

Hat truss \& braced core

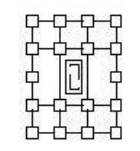

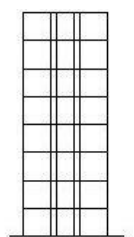

Frame and solid core
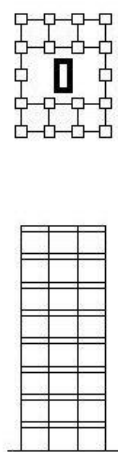

Flat slab

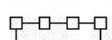

뭄ㅁ

Ф口ㅁ

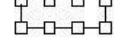

무의

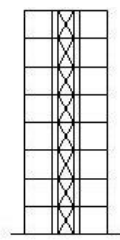

Frame and braced core
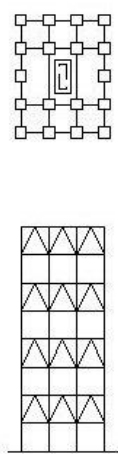

Staggered truss

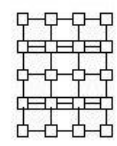

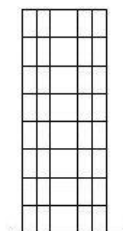

Frame and shear walls

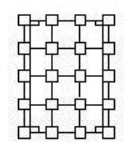

wing trusses
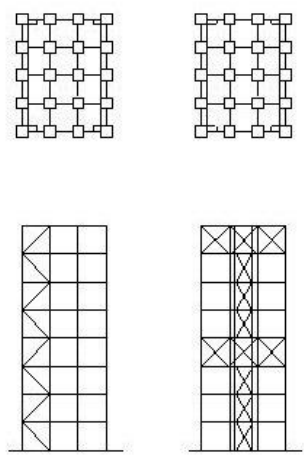

Braced Hat/belt trusses frame \& braced core
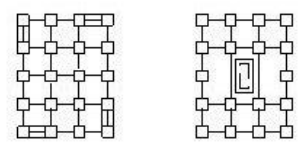


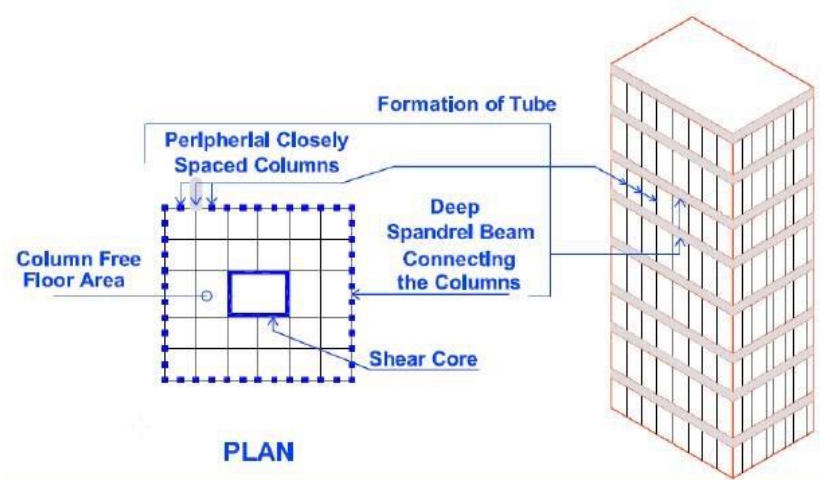

For framed tube structures the lateral resistance is given by very stiff moment resisting frames that form a tube around the perimeter of the building. The frames consists of closely spaced columns, 2-4 meters between Centre, connected by girders.

The tube carries all the lateral load and the self-weight is distributed between the outer tube and the interior columns or walls. For the lateral loading the perimeter frames aligned in the load direction acts as webs of the tube cantilever and those perpendicular to the load direction acts as flanges.

The tube structure is suitable for both steel and reinforced concrete buildings and has been used in the range of 40-100 stories. Framed tube systems have been the most significant modern development in high-rise structural forms and is easily constructed and usable for great heights.

- For the aesthetics of the tube structure the enthusiasm is mixed, some like the logic of the clearly expressed structure while others criticize the grid-like facade as small windowed and repetitious.

\section{Disadvantage with the framed tube structure:}

The efficiency for the flange frames, for lateral loading, which tend to suffer from shear lag with the result that the mid columns are less stressed than the corner columns and therefore not contributing as much as they could.

\section{B) Bundled tube system:}

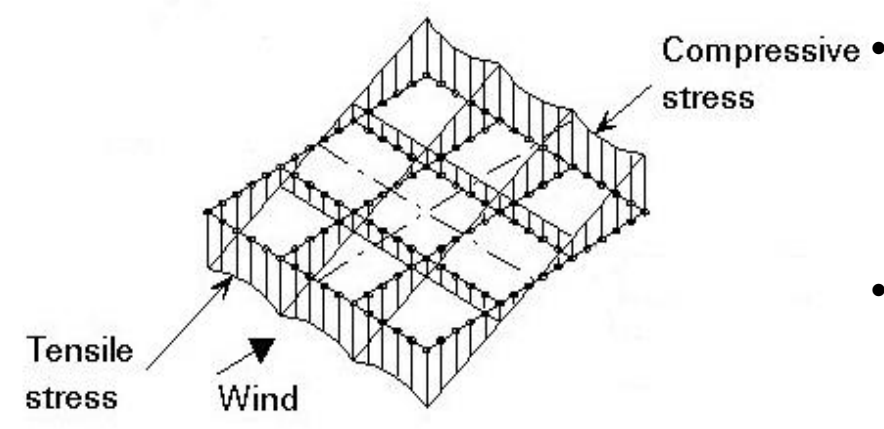

- The bundled tube structure consists of four parallel rigid frames in each orthogonal direction, interconnected to form nine bundled tubes, The principle is the same as for the single tube structure where the frames in the horizontal load direction acts as webs and the perpendicular frames acts as flanges.

- By introducing the internal webs the shear lag is drastically reduced and as a result the stresses in the columns are more evenly distributed and their contribution to the lateral stiffness is more significant. This allows for the columns to be spaced further apart and to be less striking.
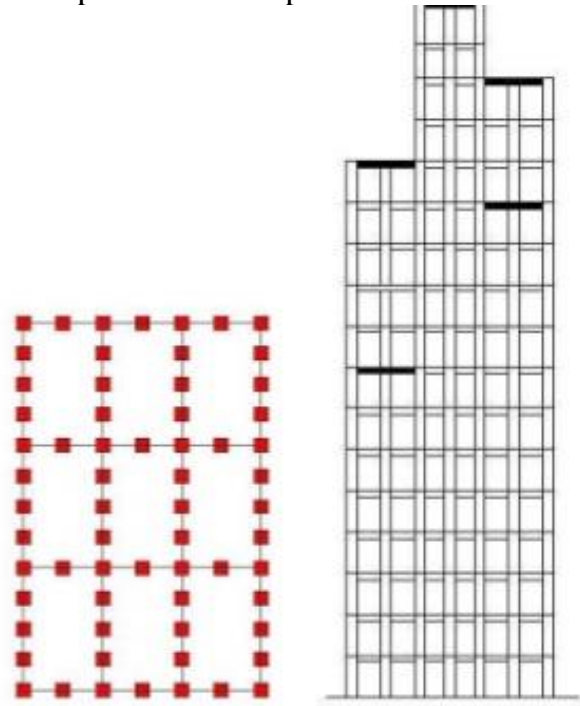

C) Tube in tube system

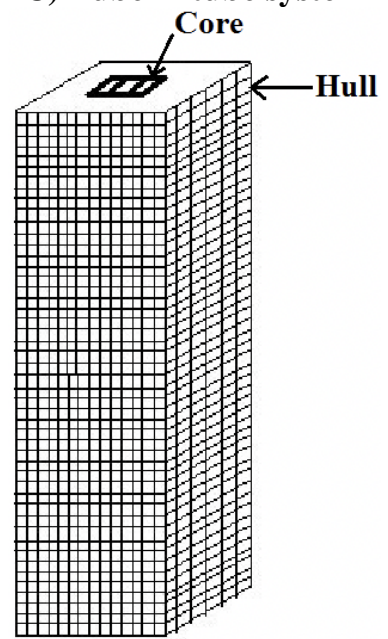

What differentiates the tube in tube concept from other structural systems is that an outer framed tube (hull), is working together with an internal tube (core), usually elevator shafts and stairs, to resist both the lateral and vertical loading.

- This provides increased lateral stiffness and can be seen as the shear and flexural components of a wall-frame structure.

\subsection{Diagonalised- and rigid frame}

- In braced frames the lateral resistance is given by diagonal members that, together with the girders, form a web of vertical trusses, where the columns acting as chords, Bracing systems are highly efficient of resisting lateral loads. This due to the horizontal shear in the building is resisted by the horizontal components resulting in tensile and compressive actions in the web members. 
- The bracing system is an almost steel exclusive system since the diagonals are inevitably subjected to tension for one or the other direction of the lateral loading. Braced systems are able to produce a very stiff lateral structure for a minimum of additional material which makes it economically efficient for any height.

- The major disadvantage with diagonal bracing is that it is limiting the internal planning and the location of windows. Furthermore, the connections to the diagonals are expensive to fabricate and erect.

- In rigid frame structures the columns and girders are joined together by moment resistant connections. The lateral stiffness of a rigid frame depends on the bending stiffness of the columns, girders and connections in-plane. This type of structure is ideally suited for reinforced concrete buildings because of the stiffness from rein- forced concrete joints.

- For steel, these connections can be made although they are expensive. An advantage with rigid frame structures is the possibility of planning and fitting of windows because of the open rectangular arrangement.

- A disadvantage is that the self-weight is resisted by the action from rigid frames. Negative moments are induced in girders adjacent to columns causing the mid-span positive moments to be significantly less than in a simply supported span.

- For buildings where self- weights dictate the design, usually below 10 stories, economics in member sizes that arise from this effect tend to be offset by the increased cost of the rigid joints.
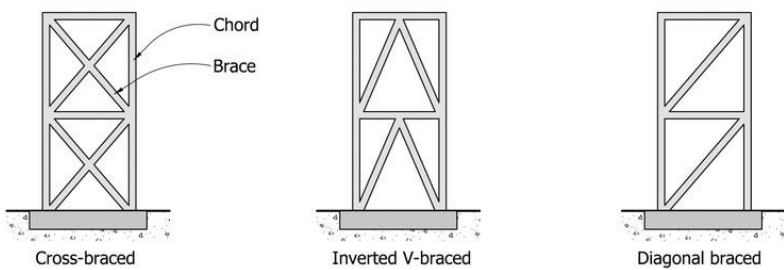

Tension and compression
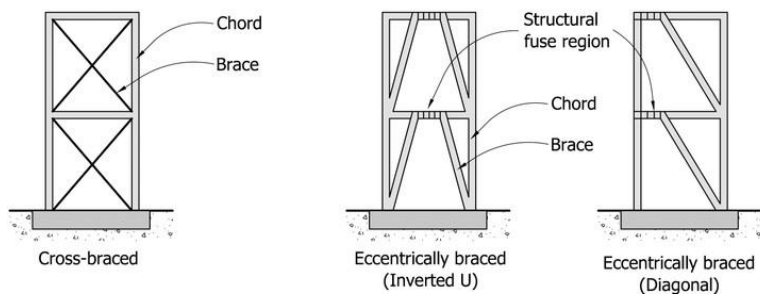

Tension-only (Inverted U)

(Diagonal)
Eccentricall braced Eccentric

E) Outrigger system

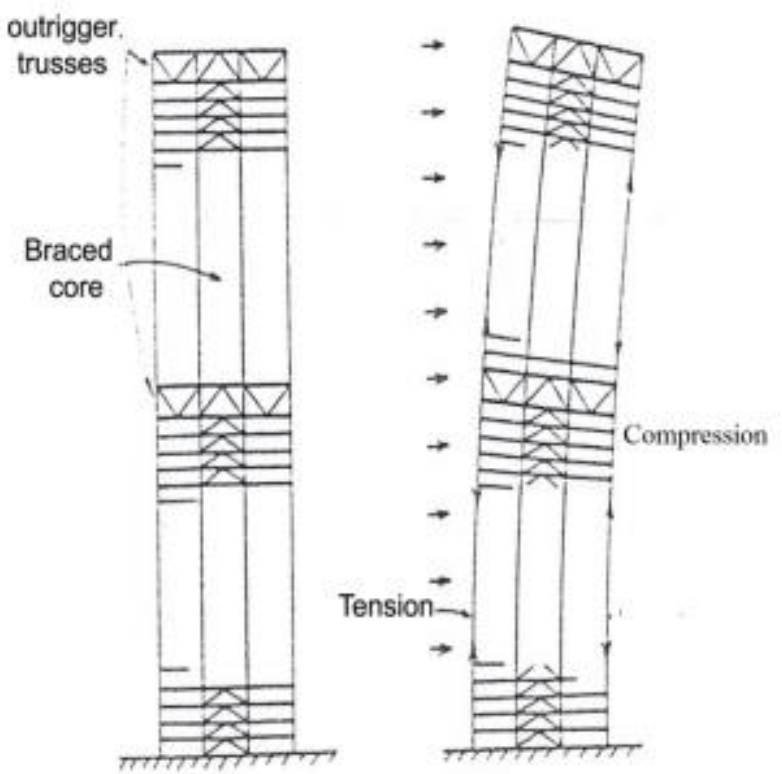

The outrigger system is an efficient structural form that consists of a central core with outriggers, connecting the core to the outer columns. The central core contains of either braced frames or shear walls.

When the building is loaded laterally the vertical plane rotations are resisted by the outriggers through tension in the windward columns and compression in the leeward columns, This is augmenting the lateral stiffness of the building and reducing the lateral deflections as well as the moments in the core.

In addition, the outriggers join the columns and make the building behave almost as a composite cantilever. Even the perimeter columns, those not directly connected to the outriggers, can be used to increase the lateral resistance of the building by connecting all the perimeter columns with a horizontal girder around the building's facade.

Multilevel outrigger systems can provide up to five times the moment resistance of a single outrigger system. Outrigger systems have been used for buildings up to 70 stories but the concept should hold for even higher buildings.

\subsection{Wind control system}

Wind-load has to be considered when designing high-rise buildings. Up to 10 stories the wind-load rarely affects the design. However, for taller buildings the effect is more crucial. Over the past years new materials with higher strength have been developed. This in combination with more innovations in architectural treatment and advances in methods of analysis have made high-rise buildings more efficient and lighter, which also means more prone to deflections and sway.

Wind-load can be divided into both static and dynamic loading depending on the time period. For long periods of time the load can be seen as static and for shorter time 
periods as dynamic. In this section the dynamic response from wind is investigated.

The dynamic wind pressure produces sinusoidal or narrowband random vibration motions on the building in both alongand across-wind direction as well as rotation about the vertical axis, The magnitudes of the displacements depends on the wind velocity distribution and direction but also on the mass, stiffness and shape of the building.

For some cases the effects from the across-wind actions are greater than the along-wind actions on the building. Even though the wind-load is dynamic in short periods of time it is often replaced by an equivalent static load representing the maximum magnitude in the design stage.

The dynamic response is considered when a building is relatively flexible to investigate the stress levels and the accelerations that may affect the comfort of the occupants.
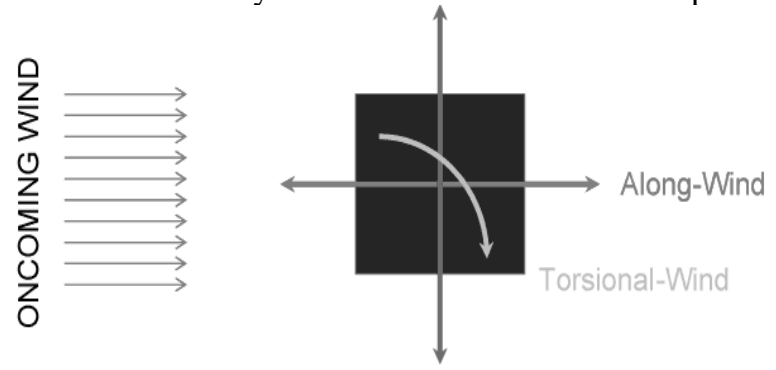

Across-Wind

- Wind is a phenomenon of great complexity because of the many flow situations arising from the interaction of wind with structures. Wind is composed of a multitude of eddies of varying sizes and rotational characteristics carried along in a general stream of air moving relative to the earth's surface. These eddies give wind its gusty or turbulent character.

- The gustiness of strong winds in the lower levels of the atmosphere largely arises from interaction with surface features. The average wind speed over a time period of the order of ten minutes or more, tends to increase with height, while the gustiness tends to decrease with height.

- The wind vector at a point may be regarded as the sum of the mean wind vector (static component) and a dynamic, or turbulence, component

\section{$V(z, t)=V(z)+v(z, t)(1)$}

- A consequence of turbulence is that dynamic loading on a structure depends on the size of the eddies. Large eddies, whose dimensions are com- parable with the structure, give rise to well corre- lated pressures as they envelop the structure.

On the other hand, small eddies result in pressures on various parts of a structure that become practically uncorrelated with distance of separation. Eddies generated around a typical structure are shown in below figure

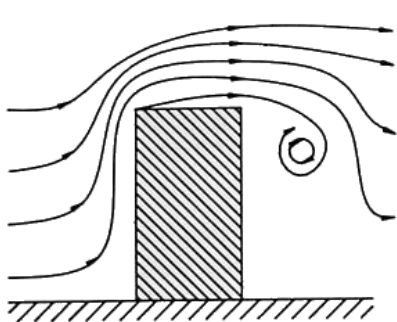

a) elevation

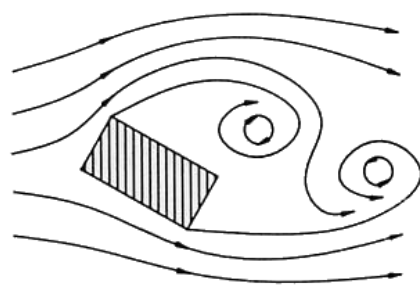

b) plan
Some structures, particularly those that are tall or slender, respond dynamically to the effects of wind. The best known structural collapse due to wind was the Tacoma Narrows Bridge which occurred in 1940 at a wind speed of only about $19 \mathrm{~m} / \mathrm{s}$. It failed after it had developed a coupled torsional and flexural mode of oscillation.

There are several different phenomena giving rise to dynamic response of structures in wind. These include buffeting, vortex shedding, galloping and flutter. Slender structures are likely to be sensitive to dynamic response in line with the wind direction as a consequence of turbulence buffeting.

Transverse or cross-wind response is more likely to arise from vortex shedding or galloping but may also result from excitation by turbulence buffeting. Flutter is a coupled motion, often being a combination of bending and torsion, and can result in instability.

An important problem associated with wind- induced motion of buildings is concerned with human response to vibration and perception of motion. At this point it will suffice to note that humans are surprisingly sensitive to vibration to the extent that motions may feel uncomfortable even if they correspond to relatively low levels of stress and strain. Therefore, for most tall buildings serviceability considerations govern the design and not strength issues.

\section{Natural frequencies and resonance}

The first modes of a building are of interest when investigating the dynamic response from wind-load. These are the lateral deflection in both directions as well as the rotational mode around the vertical axis. The modes being excited when a building is relatively tall or large, making the wind gusts not acting simultaneously on all parts and thus will tend to offset each other's effect. 
- The stiffness of the building affects the resonance frequencies. If the building is stiff, the resonance frequencies will be relatively high and the dynamic deflections will not be significant. In addition, the main design parameter to be considered is the maximum loading during the building's lifetime. The building can then be seen as static and analyzed for an equivalent wind-load.

- On the other hand if the stiffness is low the building is flexible and the resonance frequencies will become lower. This leads to that the response will depend on the frequency of the fluctuating wind forces. The building will tend to follow the fluctuating wind actions below the fundamental frequency and will be attenuated at frequencies above.

- However, at frequencies at or close to the natural frequencies the response will be amplified which may cause the dynamic deflections to be greater than the static deflections. In this case the lateral deflection becomes an important design parameter and the building is classified as dynamic.

- For flexible buildings the oscillations may interact with the aerodynamic forces which may lead to instability in form of galloping oscillations, vortex-capture resonance, divergence and flutter. To predict the structural response from wind-load there are two important evaluations to do:

The prediction of the occurrence of various mean wind velocities and their associated directions.

The prediction of the maximum dynamic response of the building with the given occurrence of the wind.

When a building is excited by wind-load the wind-force tend to be random in amplitude and spread over a wide range of frequencies. The building's response is then decided by the wind energy available in the narrow bands close to the natural frequencies of the building.

The major part of the exciting wind energy often occurs at frequencies lower than the fundamental frequency of the building and the energy decreases with increasing frequency. This makes it necessary to only con- sider the building's response at the three first modes, two lateral and one rotational, higher modes being rarely significant.

The response to the along- and across-wind arises from different forcing mechanics where the along-wind is primarily to buffeting effects caused by turbulence and the across-wind primarily to vortex shedding. The across-wind response is of special interest with regard to the comfort of the occupants.

\section{HUMAN PERCEPTION LEVEL}

\section{window glazings in the highrises}

The high-tech, high-strength glazing that covers today's super tall buildings - skyscrapers over 1,200 feet, like One World Trade Center and theBurjKhalifa , in Dubai - is as important to the buildings' performance as the steel and concrete inside it.When it comes to super tall ,the main

\begin{tabular}{|c|c|c|}
\hline RANGE & $\begin{array}{c}\text { ACCELARATION } \\
{\left[\mathrm{m} / \mathrm{s}^{2}\right]}\end{array}$ & Effect \\
\hline 1 & $<0.05$ & $\begin{array}{l}\text { Humans cannot perceive } \\
\text { motion }\end{array}$ \\
\hline 2 & $0.05-0.10$ & $\begin{array}{c}\text { Sensitive people can perceive } \\
\text { motion; hanging objects may } \\
\text { move slightly }\end{array}$ \\
\hline 3 & $0.1-0.25$ & $\begin{array}{l}\text { Majority of people will } \\
\text { perceive motion level of } \\
\text { motion may affect desk work } \\
\text { long-term exposure may } \\
\text { produce motion sickness }\end{array}$ \\
\hline 4 & $0.25-0.4$ & $\begin{array}{l}\text { Desk work becomes difficult } \\
\text { or almost } \\
\text { impossible } \\
\text { possible }\end{array}$ \\
\hline 5 & $0.4-0.5$ & $\begin{array}{c}\text { People strongly perceive } \\
\text { motion difficult to walk } \\
\text { naturally standing people may } \\
\text { lose balance }\end{array}$ \\
\hline 6 & $0.5-0.6$ & $\begin{array}{c}\text { Most people cannot tolerate } \\
\text { motion and are unable to walk } \\
\text { naturally }\end{array}$ \\
\hline 7 & $0.6-0.7$ & $\begin{array}{c}\text { People cannot walk or tolerate } \\
\text { motion }\end{array}$ \\
\hline 8 & $>0.85$ & $\begin{array}{l}\text { Objects begin to fall and } \\
\text { people may be injured }\end{array}$ \\
\hline
\end{tabular}

concern is wind. Close to the ground, wind is disrupted by trees, hills, and other buildings. But as a building rises to super tall height above the so called $\mathbf{6 . 3}$ boundary layer those obstacles fall away.
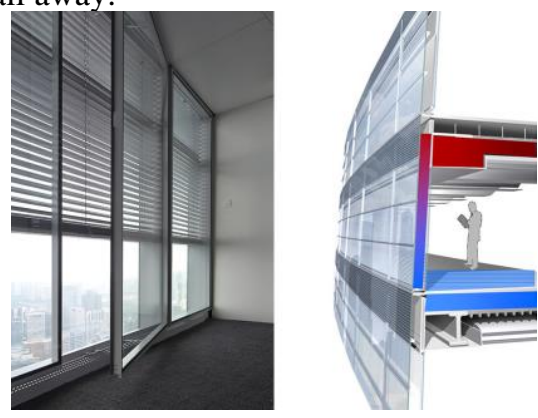

sections for details

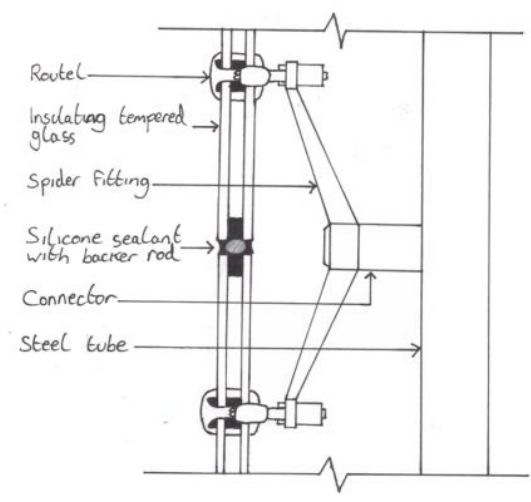


The tower faces the full, unobstructed force of the wind. And the building gets it both from the front and back: wind that hits head on pushes the glass in, while the wind that whips around the side creates eddies of low pressure that suck the glass out. In fact, the suction forces can be even stronger than the head-on pressure.
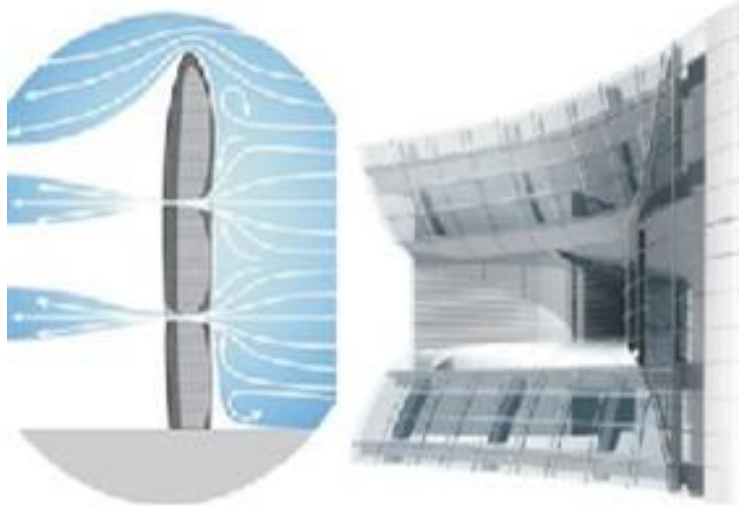

The higher you go, the more complex the wind effects get. "These pressures and suctions can travel down the tower from the high wind speeds at the top and you can have high forces at various locations on the tower even near the base," said William Baker, the head of structural engineering for the architectural firm Skidmore, Owings and Merrill (SOM), designers of the new One World Trade Center.

Another major factor is light, and heat. Tall buildings, because of their immense internal heat mass, tend to need constant air conditioning, even in the winter. Air conditioning is a skyscraper's single biggest energy expense. Super tall buildings present a unique challenge: Not only do they have high internal heat mass, but a very large proportion of their overall size is high above their neighbors, so there's nothing to block the sun. (Nor does it help that these days, most of them tend to be in desert and subtropical regions like the Persian Gulf and Southeast Asia.)

To make things even more complicated, the skin of super tall buildings is almost entirely glass, with a premium placed on tall and wide panes to offer maximum unobstructed views. "What's become popular is glass that is slab to slab, or floor to floor, up to 14 feet high," said Bruce Milley , an architecture design manager for Guardian Industries Corp., one of the main suppliers of glass for super tall towers.

And it's not wholly an aesthetic choice: Glass is cheaper than masonry and steel, and it weighs significantly less. "Glass is one of the cheaper building components," said Brian Dawley, a senior technical services representative for Viracon, another major glass supplier for super tall. "It not only looks good, but it performs well, too."

The problem is, panes that large have to be incredibly strong to withstand high wind forces, and they have to be designed in a way to compensate for the enormous amount of light they let in.

Two decades ago, many of these challenges would have been insurmountable - the technology simply wasn't there. But a lot has happened in the intervening years. "These days glass isn't just glass," said Peter Weismantle, the director of super tall technology at Adrian Smith + Gordon Gill Architecture, which designed the 3,280-foot Kingdom Tower in Jeddah, Saudi Arabia.

The first advance is in the manufacturing of the glass itself. Until recently, architects were limited by the size of the glass panes that companies like Guardian Industries could produce.

Advances in so-called flat-glass production, in which molten glass is poured onto a bed of liquid tin and then slowly cooled, manufacturers can now produce thick glass panes several meters wide. "In just the last ten years, we've seen that manufacturers can do larger and larger pieces of glass," said Steven Ball, a structural engineer John A. Martin and Associates, which specializes in part in super tall design. "Nowadays they can do six-meter-wide glass, if not more.

The raw, or annealed, glass is placed in an oven and then rapidly cooled, a process called heat strengthening, after which manufacturers or fabricators apply layers of metal coatings to achieve various performance qualities. Such coatings are applied in nanometer-thick layers, as thin as a one-thousandth of a human hair, often several on top of each other in a custom "recipe" designed to meet a building's unique needs. For example, a client might want a glass that allows in maximum light but minimum heat.

Finally, for super tall, the glass pieces will be cut and either laminated together or configured with a fraction of an inch of air between them, known as double glazing (for maximum strength, many super tall towers require triple glazing, with a laminated pair of glass panes and another thinner, single pane).

The result is a high-tech glass barrier that can be almost an inch thick: strong enough to withstand hurricane-force winds and reflect all but a fraction of the heat pouring across the Arabian Desert, yet flawlessly clear enough to appear invisible.

\section{CHAPTER 5 SAFETY MEASURES}

\subsection{Fire safety \\ GENRAL :}

Fire safety in skyscraper buildings has been a challenge for fire experts ever since these types of buildings came into being.

It is much more difficult to design a fire safety plan for high rise buildings due to the following conditions:

Longer egress times and distance

More complex evacuation strategies

Fire department accessibility

Smoke movement

Fire control

Higher population

\section{Fire-resistant construction.}


High rise building should be designed and constructed using fire-resistant materials so the fire won't easily spread. The building should also be separated into compartments to prevent the fire from spreading to the other levels or areas.

\section{Have a Fire Safety Plan and post them on public areas.}

Fire Safety Plans provide occupant safety in the event of a fire and allows effective usage of the building's fire safety features. Fire safety plans also to minimise the possibility of fires. A good fire safety plan should include emergency procedures, preventative maintenance processes, and instructions on what to do during a fire.

\section{Fire alarm system.}

Having a working fire alarm system is critical for all buildings, but more so for high buildings. An alarm system is designed to alert people when a fire breaks out, giving them more time to evacuate. This is crucial for high buildings because more people needs to be evacuated and they all have to use the stairs. You can choose from the many types of fire alarms like smoke detectors, thermal detectors, sprinkler flow switches etc.

\section{Fire escapes.}

The only way to evacuate the building during a fire is through the stairs. Aside from the usual fire escape, high rise buildings should have interior fire-proof stairwell shafts. This stairwell should have signs indicating which floor level you are on and also the nearest crossover floors. Having an interior fire-proof stairwell increases the chance of surviving for the occupants.

\section{Automatic fire-suppressing systems (sprinklers) should be installed on every floor of the building.}

Having sprinklers installed helps put out the fire and prevents it from getting bigger. Fire suppression systems help control fire and prevents it from spreading to another area.

\section{CHAPTER 6 CHALLENGES IN SKYSCRAPERS}

Fires in high-rise buildings present a number of significant challenges to fire crews. Firstly, and most obviously, the sheer height of these buildings means that crews' water hoses are often unable to reach the flames.

The average fire hose can spray up to $50 \mathrm{ft}$, but a high-rise building is defined as anything from $75 \mathrm{ft}$ upwards - and in the case of the Dubai tower over 1,000ft.

Fire-fighters therefore have to enter the building, locating the entrances, exits, stairwells, before they can even begin fighting the outbreak. These minutes could allow the fire to spread further and prevent fire crews from knowing the severity or location of the outbreak.

Ok, so how are fires fought at such heights?

To combat this, engineers and architects design the buildings so that fires are contained, limiting the spread of flames, gas or smoke in a process known as "fire compartmentation".

The rough rule of thumb is that any outbreak should be able to burn itself out without external intervention, and without the building collapsing, allowing for the evacuation of occupants above and below the fire.

This strategy means that (for example) elderly or disabled residents can be "defended in place" when they are 200 stories up. It also leads to the counter-intuitive notion that were you to be in a super tall building during a fire, your best course of action may be to stay put.

'Fire compartmentation' strategy

Building are constructed with fire-resistant features, such as automated doors - which close when a fire is detected - or barriers throughout floors that are designed to slow fires.

Among the most dangerous high-rise fire outbreak occur in office blocks, where large open-plan floors allow flames to spread easily and terrifyingly quickly.

Many skyscrapers are constructed like metal boxes within metal boxes (although this is changing as more innovative design becomes widespread) in buildings such as these however, each 'box' is protected by fire-proofed material that helps contain the outbreak.

Compartmentation

iscepiWhilst compartmentation is a requirement of the Building Regulations in certain places, it has further benefits:

It helps to prevent rapid fire spread within the building; istepi It reduces the chances of a fire becoming large, on the basis that large fires are more ssepidangerous to occupants, fire and rescue personnel and other relevant persons;

It helps to reduce the risk of total loss of a floor or building thus reducing the impact on business continuity; and istép'

Provides the capacity for staged or progressive evacuation and refuge 'spaces'. 'istep'

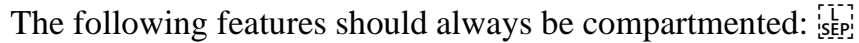
Escape routes; [is.pi]

Protected staircases or fire-fighting staircases; istepí

Protected corridors for dead-end situations; is isp?

Vertically rising shafts that penetrate through the horizontal compartmentation (lift shafts, risers etc.); is ipep

Walls common to two or more buildings; iLẸ:

Premises with a sleeping risk; istepi

Plant rooms and areas where intended activity or content involves a high risk of fire;

Areas where persons may be required to utilize some form of airlock or sterilization system to make their escape; and Separate domains (tenants etc.).

60 minutes fire resisting compartmentation may be required where there are business critical is ispifacilities, areas containing high value, or irreplaceable information etc. istep?

\section{Doorways}

Corridors that lead to alternative means of escape do not need to be protected corridors and thus the doors on these corridors (except cross-corridor and other specifically identified doors) do not need to be self-closing fire doors. In all other areas the risk of breaches due to fire doors being wedged open is considerable and will result in the additional cost of provision of required approved hold open devices. 
Compartmentation should avoid crossing doorways wherever possible so as to reduce the number of doors required as fire doors.

Penetrations

Over time, for various reasons, the use of a building may change, and a need arises to put a breach through a fire resisting wall or floor. Whilst it is impossible to anticipate every possible reason for this being done there is one common reason which accounts for the vast amount of these breaches and that is the running of cabling or wiring. It is therefore, important to consider what passive fire protection can be included into fire compartmentation to pre-empt the need for future penetrations. The inclusion of devices such as fire sleeves to allow for the running of cables when installing fire compartment walls will provide the end user and future contractors with a quick and safe way of running cable through compartment walls.

Intumescent protection sleeves with internal smoke barriers shall be installed where cables pass through fire compartment walls. The sleeve should be of suitable size to allow for future extra cabling.

Where, during the process of refurbishing or upgrading existing buildings, the opportunity arises to inspect existing compartmentation the compartmentation shall be inspected and any deficiencies made good as part of the upgrading or refurbishment works.

In all cases, where there is a need to breach existing compartmentation, the Fire Safety Advisor shall be notified prior to any works commencing and on completion of the works.

Vertical service shafts etc.

60 minutes fire resisting compartmentation is required at all access points and where services leave shafts rather than at floor levels. Detection will normally be required at the top of shafts.

Ducts and dampers

Extraction ductwork should be non-combustible and vent externally. Ductwork should be enclosed in a minimum of 30 minute fire resistant material where present in an escape route. Automatic fire dampers shall be provided where it passes through fire resisting elements; access for maintenance must be provided.

\section{Evacuation Strategies Simultaneous Evacuation}

The simplest escape strategy is to ensure that, as soon as a fire has been confirmed, all of the occupants leave the building simultaneously. The actuation of a call point or detector gives an instantaneous warning from all fire alarm sounders for an immediate evacuation.

Simultaneous evacuation is preferred in smaller buildings; however some situations require variations, for example: apartment buildings where a defend-in-place strategy is adopted by providing a high degree of fire protection, such as fire-resisting separation between individual dwellings

\section{Staged evacuation}

The operation of a call point or detector gives an evacuation signal on the storey or zone affected; an 'alert' warning signal may be given in other parts of the premises. The decision to evacuate the remainder of the occupants then rests with the management and/or The Fire and Rescue Service.

In large or complex buildings, a staged evacuation procedure may be preferred in order to provide manageable sized alarm zones and reduce disruption. This will require the alignment of fire compartmentation. It is essential that adequate means of communication between storeys or zones is provided; a public address system or voice alarm, instead of sounders, is the most suitable way to control the evacuation process.

\section{Occupant capacity}

Occupancy figures are often the deciding factor in regards to the width of escape routes, staircases and doorways. Although client specifications will be met there is often some spare exit width or occupancy capacity in completed designs which is not supplied. This information is crucial when considering changes of use, items to be placed in corridors etc.

Future flexibility of use and all restrictions must be considered and an exit capacity agreed with the University. Maximum capacities for each space, permitted by the finished design, shall be included in the Fire Safety Manual.

Where client specification or furniture plans do not indicate the number of people in office accommodation a figure of $10 \mathrm{~m} 2$ per person may be used.

Guidance recognizes that where specific or comparative data are available to demonstrate the actual maximum occupancies, this may be used instead of the standard floor space factor.

\section{Exit routes}

Single direction escape routes and rooms within rooms should be avoided. Staircases and lifts should normally be installed at the extremities of buildings.

Travel distances will account for use by people with mobility impairments. $18 \mathrm{~m}$ is the usual maximum acceptable single direction travel distance unless there are suitable compensatory features.

Display information and items are often required within corridors. Where this is the case, fixed encased display facilities are to be provided.

Where exit routes are through an open plan area, the floor surface should indicate the route and management policies should ensure that this is kept clear of any obstructions.

Access and security controlled locking systems on doors used on escape routes including automatic sliding doors that do not have a mechanical override in the direction(s) of escape, such as a normal latch with a handle operating an electrical strike plate, systems that rely on the release of Electro-magnetic locks or operate by a code, push button or reader to allow the door to open, will require special arrangements to ensure that they fail safe at all times in the event of an emergency.

Where electromagnetic locking devices fitted to doors on the means of escape do not have a manual override they shall fail safe to open:

The locks shall release on operation of the fire alarm system; :

On the loss of electrical power; is isepi 
Suitable emergency disconnection arrangements shall be provided at each locked door on the exit route, this will normally be in the form of the operation of a 'break glass' unit positioned adjacent to the door. [stepi?

Each emergency break glass unit shall: is siepi:

Be coloured green; '[LE']

Be in a prominent position suitable for escape; 'LE

Be clearly labeled; 's[-pis?

Be a double pole type that interrupts both lines of supply. istep?

\subsection{Way finding}

Illuminated escape signage shall be utilized as far as reasonably practicable and shall

Augment emergency lighting. Non-illuminated signage should be photo-luminescent. All signage should be as large

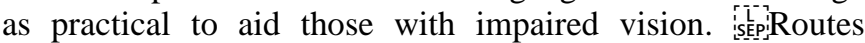
specifically for the use of people with mobility impairments (i.e. alternatives to staircases) should be indicated with the standard wheelchair user symbol in green; those not suitable with the same crossed through added to the standard 'running man'. is i i There should be clear color contrast of doorways, edge marking of stairs and steps etc. to aid those with impaired vision. istepi

Lifts

All lifts are to be to evacuation standard unless use of an accommodation lift can be justified by risk assessment. is supplemented with the disabled exit route sign where suitable.

\subsection{Emergency lighting}

is monitored, addressable emergency lighting system is to be used to reduce maintenance costs and provide accurate records of maintenance required by statutory regulations. istep In whole or part floor refurbishments, fully monitored, addressable emergency lighting systems are to be considered as part of the project and provided with capacity sufficient so that other parts of the building can be added as part of strategic maintenance funding in the future.

\section{Doors:}

Final exit doors shall be fitted with single action locks and provide level exit or be ramped to 1:20 max.

All fire doors shall:

Be fitted with intumescent strips and smoke seals; 'is

Be of contrasting colour to the walls or frame;

Be provided with disabled friendly handles usable by a

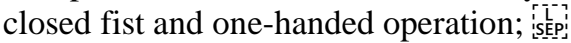

Be operable one handed with a maximum of $30 \mathrm{kn}$ force opening force; '[LE

To allow flexibility in future usage. All room door sets, corridor fire door sets and partitions adjoining circulation corridors must be of a 1/2-hour fire resisting standard and capable of being fitted with self-closing devices. [i[

Each door must be marked and labelled as being of fire resisting construction. iscepí

Where the fire risk assessment indicates a need for room doors to be designated as fire stsepidoors they must be marked 'Fire Door -- Keep Closed' and be fitted with a self-closer, 'i[s-p'] Mains powered free swing closing devices are preferred on room doors likely to be wedged open; ;sicps]
Corridor doors are generally to be provided with magnetic hold open devices interlinked to the alarm system; where used at the junction of alarm zones they must release on activation of either zone; is íp.'

Where magnetic door locks are used at the junction of alarm zones they must release on activation of the alarm system of

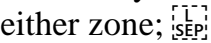

All electrical door closers, locks and hold opens must fail

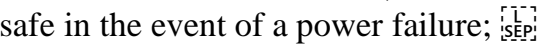

All doors on an escape route and final exits that incorporate a magnetic security device or are automatic doors that require an access card or entry code must fail safe to the open position in the case of an alarm activation; [SEE]

All doors on an escape route and final exits that can be secured by a manual key lock must have a handle or other simple fastening that can be easily operated, without the need for a key or other specific technical knowledge, from the side approached by people making their escape; iLẸ

\section{3 evacuvation technique}

\section{Occupant Evacuation Elevators (OEE)}

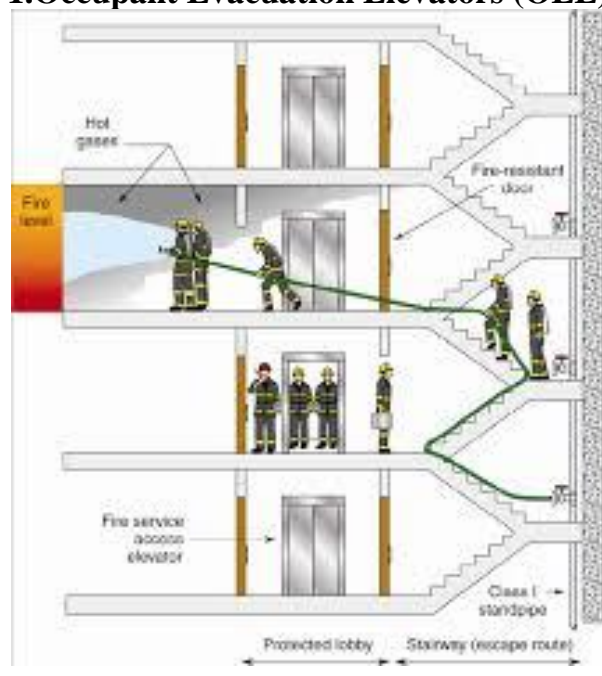

Despite technological

advancements, staircases remain the dominant means

of egress for occupants during an emergency. Elevators are typically off limits for evacuation, especially in where smoke or fire are involved. Technical provisions for OEEs were very recently added to building codes; as such insufficient attention has been paid to embed

these facilities into building disaster management systems (A merican Society of Mechanical Engineering Safety Code for Elevators and Escalators2013 [ASME A17.1-2016]/Canadian Standards Association Safety Code for Elevators and Escalators 2016 [CSA B44-16]).There are several challenges tothe use of elevators in emergencies, such assafety concerns, technical restrictions, and human behavior patterns. At the same time, the unique features ofelevators could benefit an evacuation system and justify an investment into the resolution of the challenges.In the 9/11 disaster, the number of occupants killed in the WTC-2 was half the number of WTC-1. A 2012 federal investigation of the evacuation revealed that the occupants' use of elevators in WTC-2 was part of the reason. This supported the ideathat elevators could be very helpful during evacuations, at leastunder some specific circumstances (Averill et al 
2001). Starting in the 2009 edition of the International Building Code (IBC), buildings with a height of more than $128 \mathrm{~m}$ are required to have an additional egress stairway (IBC2015 §403.5.2). However, buildings equipped with OEE are exceptions to this clause

\subsection{Evacuvation chute:}

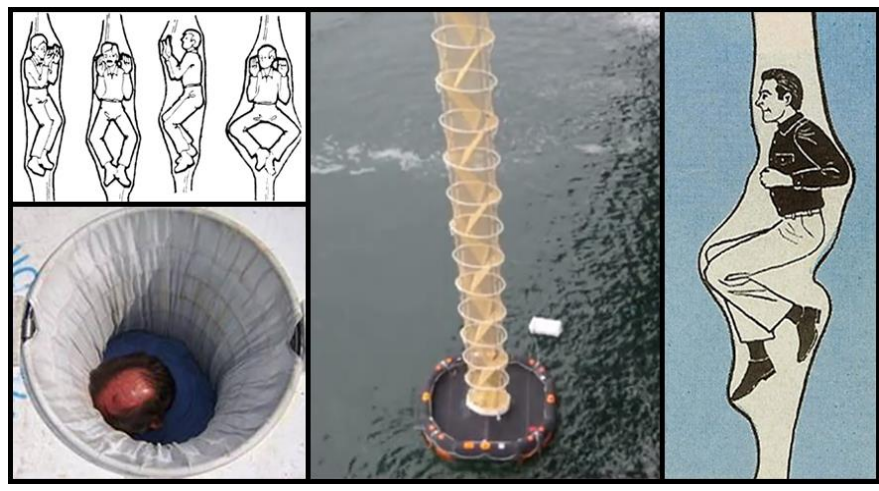

Their flexibility allows for compact storage, rapid deployment, and a gentler braking and controlled descent of users, as compared to traditional metal designs. Fabric tubes may also incorporate inflatable elements to lend some degree of structuralrigidity and stability to the escape chute. The fabrics chosen must have fire retardant properties as well.

In addition to fixed escape chutes permanently installed onto buildings, mobile escape systems are produced which can be mounted on the basket of a movable fire truck ladder, or temporarily installed to a building in an emergency.

\section{4.evacuvation slide}

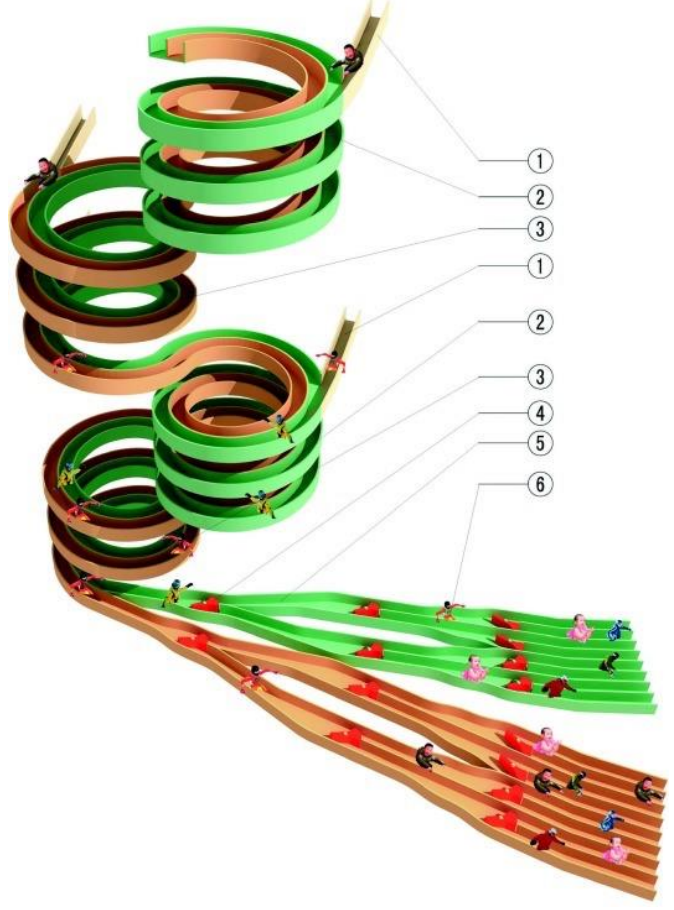

The new evacuation device mainly consists of special spiral slides and shunt valve. The projection on plane for special spiral slide is " 8 "-shape, which consists of single and double spiral slide ways. New evacuation device can be divided into two types as per sideways categories: (1) Single slide way system; (2) Dual slide way system

The working principle of new evacuation device is very simple. Just like the mono-spiral sliding ladder in children's park, the new evacuation system is very easy to use. As long as people sit or lie on the slide, by means of the gravity of the earth, they can slide down to the ground floor without any energy and physical power, and also no any manipulation technique is required. For evacuees evacuating from building with the height of a few hundred meters by means of traditional stairways, not only is the lower speed and a long time taken, but also strong physical strength is required

\section{CHAPTER 7: CONCLUSION}

The result of this study is as the skyscrapers are evolving from the initial starting of it to till new era it is developing more in numbers and countries are constructing it as a pride of their nation and wanted to have there are certain difficulties and constraints which are need to be taken into considerations

The ideas and technologies are developing in step by step of each stages this would be a positive sign to the skyscrapers even more development are going through as technology grow rapidly .Constructions techniques are also evolving with proper safety measures and construction skyscraper without major accidents to people work this is even because the development of technology.Concentration of skyscrapers would affect micro climate and urban landscapes

Being in a skyscrapers which make the feel out of the urban space and flying high the connect to the urban space and social environment is getting affected

Skyscrapers can be used properly with considerations of negative impacts on it and should be studied to give more better outcomes and proper utilization should be done further.

\section{REFERENCES}

[1] Krishna Raju .N, Pre Stressed Concrete, Tata McGraw Hill Publishing Company Ltd., New Delhi, 1988

[2] Taranath .B.S, Structural Analysis and Design of Tall Buildings, McGraw Hill, New York, 1988.

[3] Bennetts Ian \& others - Tall building structural systems.

[4] Proceedings of the Council for Tall buildings - Vol 1 to 10 Books 1997.

[5] Handbook on buiding firecodes by G.B.Menon.

[6] .National building code (NBC)Part 4-directorate of fire service.annex c.

[7] Bryan Stafford and Alex Coull, Tall Building Structures, Analysis and Design John Wiley \& Sons, NewYork, 1991

[8] Stein Reynolds Mc Guinness - Mechanical and Electrical equipment for buildings - vol $1 \& 2-$ John Wiley\& sons

[9] Tall building design:steel,concrete, and composite systems.by Bungale s.Taranath.-CRC press. 